\title{
Los vasos litúrgicos mitraicos $\left(^{\star}\right)$
}

\author{
Julio Muñoz Garcia-Vaso $\left({ }^{* *}\right)$
}

No quisiéramos comenzar este artículo sin referirnos a la dificultad de concretar la función específica de los vasos litúrgicos mitraicos dentro de este culto. También en éste, como en tantos otros aspectos de dicha religión, los Misterios de Mithra, siguen siendo aún hoy misterios, como algún investigador ha señalado con ironia.

Entre las numerosas investigaciones de detalle sobre la liturgia mitraica, la más importante y controvertida es, sin duda, la de Albrech Dieterich '. Según Cumont, el citado autor quiso demostrar, no sin falta de ingenio, que un texto místico, inserto en uno de los Papiros Mágicos de París, es en realidad un fragmento de la liturgia mitraica; pero lo cierto es que Cumont comparte el escepticismo que ya manifestaba al respecto Reitzenstein ${ }^{2}$, remitiéndose a las razones que él mismo había manifestado en otro de sus trabajos ${ }^{3}$. Dieterich respondió brevemente a las objeciones de Cumont, pero sin llegar a convencerlo ${ }^{4}$. En opinión de $\mathrm{Cu}-$

\footnotetext{
"Expresamos nuestro más sincero agradecimiento a la Dra. D. Ana María Vázquez Hoys, tanto por la supervisión efectuada, a nuestro ruego, del contenido del presente articulo, que ha servido para enriquecerlo con sus sugerencias y especial conocimiento de la iconografia de la serpiente en los contextos arqueológicos de las religiones antiguas, como por su autorización para ilustrarlo con fotografías de vasos litúrgicos mitraicos obtenidas por ella en el Museo de Colonia (Alemania). A su generosidad y a la de Don E. Alcorta Irastor$\mathrm{za}$, descubridor, en el curso de recientes excavaciones efectuadas en Lugo, de un vaso litúrgico, de posible adscripción mitraica, prácticamente inédito, debemos también los datos $y$ fotografias del mismo, que incluimos en el presente trabajo.

(") Colaborador del Departamento de Prehistoria e Historia Antigua, UNED, Madrid

'Dieterich, A., Eine Mithrasliturgie. Leipzig 1903.

2 Reitzenstein, Neue Jahrbuch f. das class. Altertumwiss, 1904, pág. 192.

${ }_{4}^{3}$ Cumont, F., en la Revue de l'inst. publiq. en Belgique, XLVII, 1894, págs. 1 ss.

${ }^{4}$ Dieterich, A., Archiv für Religionswiss, 1905, pág. 2.
} 
mont, el autor del fragmento discutido pudo haber dado perfectamente al dios que pone en escena la apariencia exterior 'de Mithra, pero desconocía cuál era la escatología de los Misterios persas ${ }^{5}$.

Sabemos perfectamente y por testimonios positivos, señala Cumont, que la doctrina mitraica enseñaba el dogma del tránsito del alma a través de las siete esferas planetarias, y que Mithra guíaba a los fieles en su ascensión hacia la morada de los bienaventurados. Pero ni una ni otra doctrina se halla en la uranología fantástica de los maguseos mitraicos. El nombre de Mithra, como también el de los magos Zoroastro y Ostanes, sirvió, en opinión de Cumont, para poner en circulación un «pastiche egipcio" ${ }^{6}$.

Desde que Cumont manifestara por vez primera las citadas objeciones en relación con la autenticidad del mencionado fragmento litúrgico, nada ha cambiado en el campo científico. Y así R. Turcan, en la actualidad primera autoridad francesa en el campo de los Estudios Mitraicos, refiriéndose, en su más reciente libro, al impacto del mitraismo en Egipto, señala que la pretendida liturgia de Mithra del célebre papiro comentado por Dieterich nada tiene que ver con el dios de los misterios ${ }^{7}$.

En opinión de Turcan, para el estudio de la liturgia mitraica no tenemos nada comparable a los testimonios de Justino Mártir y, sobre todo, de Hipólito, concernientes al banquete de iniciación de los cristianos. En tal sentido, algunas indicaciones de Justino nos informan sobre el ritual mitraico. Todavia en el siglo ll el pagano Celso, y, más tarde, hacia el año 200, el cristiano Tertuliano hacen numerosas alusiones al culto persa en el cuadro de sus planteamientos polémicos. Eubulo y Palas (¿hacia el 140?) habían dedicado sendas obras, hoy desaparecidas, a los Misterios de Mithra. El neopitagórico Numenio de Apamea las había utilizado, y en la segunda mitad del siglo III, el neoplatónico Porfirio (De Abstinentia, II, 56, y IV, 16) se refiere a ellos para respaldar sus argumentaciones. Pero no nos informa más que indirectamente, como hacen otros autores griegos o latinos, cristianos o paganos, que se nutren de datos tardíos o parciales, cuando no tendenciosos y deformados. No existe, por consigüiente, ningún texto mitraico de primera mano que nos explique direc-

${ }^{5}$ Cumont, F., Les Religions orientales dans le paganisme romain. Paris 1929 (edic. esp. Madrid 1987, pág. 142).

${ }^{6}$ Cumont, F., Ibidem.

7 TuRCan, R., Les cultes orientales dans le monde romain. París 1989, pág. 211: “En Egypte, l'impact est plutôt faible, en dehors du Delta (la prétendue "Mithrasliturgie" du célèbre papyrus commenté par A. Dieterich n'a rien à voir, en définitue, avec le dieu des mystères", y pág. 360, núm. 63: CIMRM, 670 y fig. 191], págs. 227-234. 
tamente el ordo del culto persa ${ }^{8}$. Algunas inscripciones incompletas descifradas o descifrables sobre los muros de la sala central del Mitreo de Santa Prisca, en Roma, han servido para ampliar algo nuestro conocimiento sobre este tema ${ }^{9}$. Pero en el estado actual de la documentación disponible, es esencialmente sobre el material arqueológico sobre el que mayormente podemos formarnos una idea de la práctica ritual en los antros mitraicos.

La imprecisión con que se nos presenta la función específica de los vasos litúrgicos mitraicos dentro de este culto es, por to tanto, consecuencia de esta misma imprecisión con que conocemos su liturgia.

La caracteristica ausencia de alusiones a esta divinidad y a su culto en las fuentes numismáticas aumenta todavía más la difícil investigación del sentido ritual de estos vasos litúrgicos mitraicos, que, como ya hemos señalado, se hace prácticamente dependiente de las fuentes arqueológicas. Afortunadamente, la adscripción de algunas de estas piezas cerámicas a contextos cultuales mitraicos es tan evidente, por las razones que luego analizaremos, que no existe duda alguna de su carácter litúrgico dentro del ritual mistérico mitraico.

La representación de un tipo de vaso, en concreto, la crátera, se repite en las manifestaciones del arte mitraico. En varios relieves germánicos, por ejemplo, aparece directamente asociada a la escena del sacrificio del toro por Mithra. La crátera forma también parte del famoso grupo iconográfico trinario león-crátera-serpiente establecido por Will en su conocida sistematización sobre el relieve cultual greco-romano ${ }^{10}$. No obstante, en este último caso, conviene señalar que la asociación iconográfica de estas tres figuras ha sido identificada en épocas no sólo mucho más antiguas, sino incluso mucho más tardias de las que la cronología atribuye a este culto, lo que hace suponer que su valor simbólico tiene raíces y ramificaciones muchos más extensas ${ }^{11}$.

8 Turcan, R., Mithra et le mithriacisme. Paris 1981, págs. 71-72.

${ }^{9}$ Vermaseren, M. J., - Van Essen, C.C., The Excavations in the Mithraeum of the Church of S. Prisca in Rome. Leiden 1965, figs. 274, 340, 347.

${ }^{10}$ WILL, E., Le relief cultuel greco-romain. Contribution a l'Histoire de l'Art de l'Empire romain (= Bibl. des Ec. franç. d'Athènes et de Rome, fasc. 183). Paris 1955.

${ }^{11}$ Küster, E., Die Schlange in der griechischen Kunst und Religion (2 Heft). Giesen 1913, págs. 1 ss; Demougeot, E., "Le Symbolique du Lion et du Serpent sur le solid des Empereur d'Occident de la Premiere moitie du Ve siecle", Revue Numismatique 150e Anniversaire 1836-1936, Vle Série- T. XXVIII, Année 1986, Societé Francaise de Numismatique ("Les Belles Lettres"), págs. 94-118, lám. VII. 
Recientemente, Turcan ha vuelto a insistir en la frecuencia con que la crátera se representaba, en las tauroctonías mitraicas, debajo del toro inmolado por esta divinidad ${ }^{12}$.

En el ya citado Mitreo de Santa Prisca, uno de estos vasos litúrgicos es transportado procesionalmente en la escena pintada al fresco en la pared izquierda de la nave central, juntamente con las ofrendas del pan y las velas (?), escena en la que los participantes se aproximan al Banquete de Mithra y Sol. Por ello, se ha supuesto que la crátera contenía la sangre o un sustituto simbólico usado en el banquete ritual mitraico, quizás vino, a menos que se trasladase vacia para luego ser llenada con la sangre del animal sacrificado, como ha sugerido Vermaseren ${ }^{13}$ y más tarde Hinnells en uno de sus trabajos sobre la Tauroctonia ${ }^{14}$.

Turcan, refiriéndose a esta misma crátera representada en Santa Prisca, difiere, en cuanto al posible contenido de la misma, de la interpretación de Vermaseren, sugiriendo que podría contener vino mezclado con agua ${ }^{15}$. Observamos ya aquí diferentes interpretaciones en cuanto al posible contenido de un mismo vaso litúrgico mitraico: ¿vino?, ¿sangre?, ¿vino mezclado con agua?. Y tampoco ha faltado quien señalase que su contenido era miel o hidromiel ${ }^{16}$. Pero además hemos de considerar también las dos posibilidades siguientes:

1. Q Que la crátera se llevará procesionalmente vacía para llenarla posteriormente de «algo".

12 TuRCAN, R., Op. cit., pág. 79: “On a vu qu'un cratère figure assez fréquemment sous le taureau qui perd son sang. Le serpent et le lion qu'on voit s'approcher avidement sont censés vouloir s'y abrevuer et, tout comme le chien, absorber la sustance vivifiante de la victime".

${ }^{13}$ Vermaseren, M. J., Op. cit., 1965, págs. 163-164: “It is highly probable that the krater is filled with wine, unless it is carried in order to be filled eventually with the blood of the slaughtered animal, particularly that of the bull», y núm. 10.

${ }_{14}$ HinnelLs, J. R., "Reflection on the bull-slaying scene", en Mithraic Studies, vol. II. London 1975, pág. 303 , admite la posibilidad de que la crátera pueda contener tanto sangre como agua: "The obvious symbolism of the krater is that it contains the blood of the bull, and its significance therefore depends on the interpretation of the tauroctony. It may also represents the spring of living water referred by Porphyry (De Antro Nympharum, XVIII)... Whether either of both of these interpretations is correct, there can be no doubt that this motif can in no way represent either the presence of evil or the theme of conflict".

15 Turcan, R., Les cultes orientales dans le monde romain. París 1989, pág. 229: "On devait aussi consacrer et partager le vin additionné d'eau dans un des ces cratères que tiennent les "lions" de S. Prisca".

${ }^{16}$ Ogawa, H., "Mithraic Ladder Symbols and the Friedberg Crater", en Hommages à Maarten J. Vermaseren, vol. II. Leiden 1978, págs. 854-873. 
2. Que se llevará también procesionalmente pero llena ya de ese «algo».

Desde el punto de vista de la investigación interpretativa de esta liturgia todos estos planteamientos serian, pues, muy diferentes.

En el Mitreo de las Siete Puertas, de Ostia, la crátera se representa en un mosaico monocromo, como símbolo del elemento agua (figs. $1.1 \mathrm{y}$ 1.2. Justino (Apolog, 1,66 ) dice que el pan y el agua se usaban en los banquetes rituales de diversos cultos, así como la sangre y el vino. Según S. Laeuchli, es posible que éste fuera el significado de la alusión de Proclo a la pegaios krater, el vaso suministrador (literalmente, "generador") de vida, aunque al referirse a él podia tener en mente otros vasos usados en ritos de purificación ${ }^{17}$.

Los primeros vasos litúrgicos mitraicos se descubrieron en contextos cultuales -mitreos- alemanes, sobre todo, de Colonia. Posteriormente, su nónima se ha visto incrementada por nuevos ejemplares descubiertos en Bélgica, en Francia e incluso en la misma Alemania.

A Swoboda, se debe la primera sistematización de los vasos descubiertos en Colonia. Su estudio vio la luz en 1937 y se centraba exclusivamente en los ejemplares decorados con serpientes ${ }^{18}$. Estos mismos vasos han sido estudiados más recientemente por Ristow ${ }^{19}$.

Otros vasos litúrgicos mitraicos han aparecido posteriormente en Eysses (Excisum), en Villeneuve-sur-Lot (Lot-en-Garonne) y en otros diversos lugares (localidades de los Valles de l'Escaut y del Dendre, en Bélgica, Tournay y Aardenburg, en los Menapiens, en Blicquy, en los Nerviens, en Cambrai, este último en el Museo de Chartreuse, etc.), y han sido estudiados por diversos autores ${ }^{20}$.

17 LaEUCHLI, S., Mithraism in Ostia. Northwester University Press, 1967, pág. 72.

18 Swoboda, E., "Die Schlange im Mithraskult", Jahresfte des österreichischen Archäologiquen Institute, XXX. Wien 1937, págs. 1-37.

${ }_{19}$ Ristow, G., Mithras in römischen Köln, EPRO. Leiden 1974, págs. 21, número 13; 30, núms. 35-37, láms. XIV-XV, figs. 15-17; XIX, fig. 22; XX, fig. 24; XXII, fig. 26; Jdem, Religionen und ihre denkmäler im antiken Köln. Colonia 1975, págs. 61-63, fig. 64 .

${ }^{20}$ AmAND, M., "Des vases mithriaques aux serpents dans l'Empire romain", en La Période Gallo-Romain, Colloque International d'Archèologie tenu à Rouan du 3 au 5 juillet. 1975, págs. 165-169; HELDENBERGH, R., "Tourinnes-Saint-Lambert. Un vicus gallo-romain. Vase à buste et à decor zoomorphique", Latomus, 35, núm. 2, 1976, págs. 520-532 y fig. 3, 6. TURCAN, R., "Chronique gallo-romain", Journal of Mithraic Studies, vol. I, núm. 2. London 1976, págs. 196-197; Idem, "Chronique gallo-romain", Journal of Mithraic Studies, vol II, núm. 2. London 1978, págs. 181-182. 


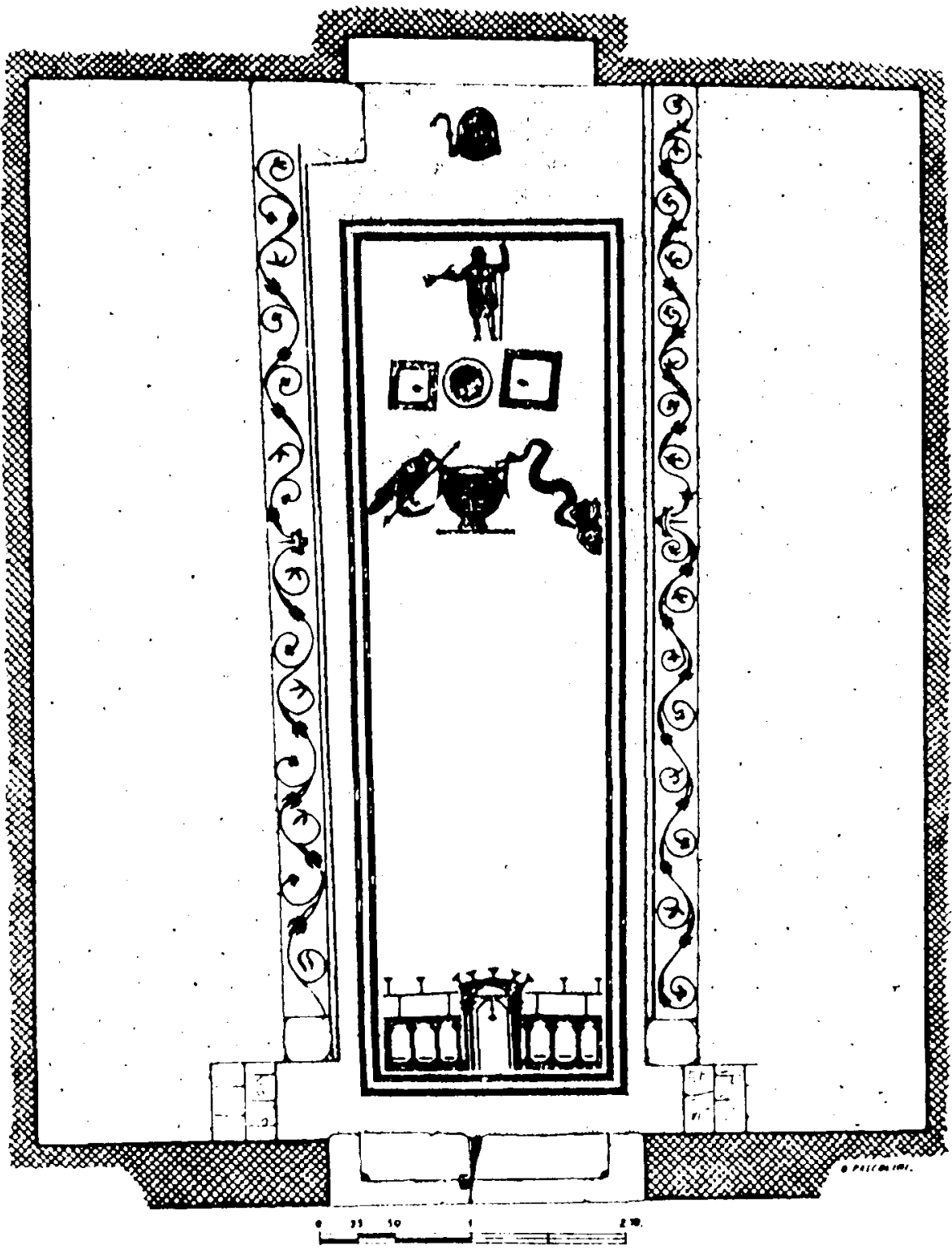

Fig. 1.1. Mosaico monocromo del suelo del Mitreo de las Siete Puertas, de Ostia, en donde se ve el conjunto iconográfico cuervo, crátera y serpiente. Dibujo: G. Pascolini. 


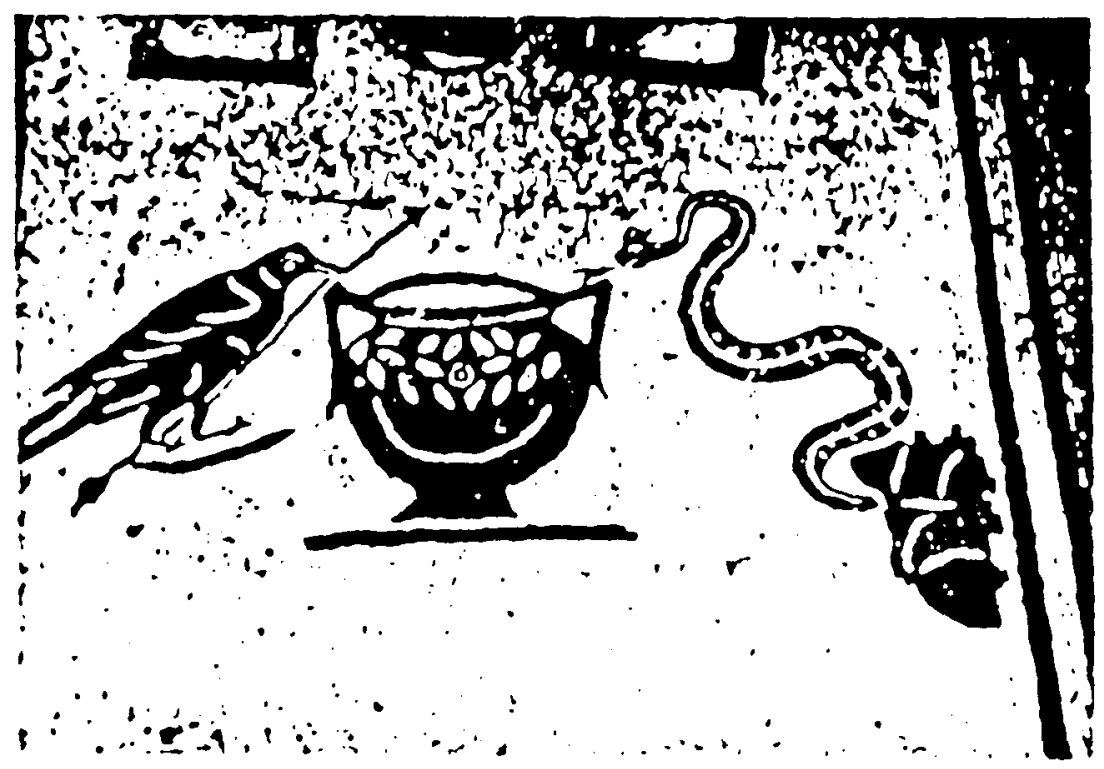

Fig. 1.2. Detalle decorativo del mosaico del Mitreo de las Siete Puertas centrado en una crátera de dos asas. Dibujo: G. Pascolini.

$H$. Vertet repara en el hecho de que, si bien la decoración de los vasos decorados con relieves de dioses y diosas del Panteón clásico, fabricados en la Galia, es muy frecuente, las decoraciones alusivas a figuras representativas de cultos orientales son muy raras ${ }^{21}$. En su limitado repertorio de materiales arqueológicos alusivos a representaciones mitraicas en vasos de arcilla en la Galia, el citado autor hacia alusión a los seis siguientes:

1. ${ }^{\circ}$ Fragmento, descubierto en Alesia en 1907, y publicado por $\mathrm{J}$. Esperandieu ${ }^{22}$, perteneciente a un vaso de tierra roja cocida, consistente en una copa de boca muy ancha, decorada con la figura en relieve de uno de los dadóforos mitraicos vestido con traje frigio. La figura original tenía la antorcha levantada, pero, al parecer, el alfarero suprimió este atributo y lo substituyó por otro con la antorcha hacia abajo. No obstante,

21 VERTET, H., "Les représentations mithriaques sur les vases d'argille en Gaule", en Actes du 88e. Congrés National des Societés Savants, Clermont-Ferrand, 1963, Secction d'Archèologie. Paris 1965, pág. 121.

22 Esperandieu, 5e Bulletin des fouilles pro Alesia, juillet, 1907, núm. 13, págs. $203-$ 205, lám. 28. 
se percibe bien todavía la espalda y el brazo izquierdo levantado del dadóforo en cuestión. El artesano pegó el otro miembro, de tosco modelado, ajustándole un pequeño cilindro de arcilla cuya extremidad inferior aplanó y dividió en tres partes, tratando quizás de simular las llamas de la antorcha. La figura viste clámide abrochada a la espalda por una fíbula circular. Vertet califica este relieve de muy malo, muy empastado, con los rasgos del rostro apenas visibles y sugiere que proviene posiblemente de un motivo muchas veces moldeado y sacado de un vaciado del mismo. También señala que se aprecia a la derecha del fragmento una aplicación que pudiera haber sido la extremidad plegada de la clámide de un Mithra tauróctono ${ }^{23}$.

2. ${ }^{\circ} \quad$ Fragmento casi idéntico al anterior, y también perteneciente a una copa. Presenta el relieve de un dadóforo y se encuentra hoy en el Museo de Clermond-Ferrand. La antorcha aparece aquí levantada, "encontrando el motivo no modificado que ha servido de punto de partida al fabricante de la copa de Alesia» ${ }^{24}$.

3. ${ }^{\circ}$ El mencionado autor relaciona estos dos motivos con otros descubiertos respectivamente en Vandée y en Londres, publicados por Dèchelette ${ }^{25}$. Representan dos personajes con traje frigio. La posición de sus manos podría ser la de un dadóforo con la antorcha levantada ${ }^{26}$.

4. ${ }^{\circ}$ Vaso en pasta y engobe rojo, con relieves superpuestos obtenidos por vaciado en molde, representando a Mithra sacrificando al toro y a la diosa Epona. Este vaso, de $25 \mathrm{~cm}$ de altura y 23 de diámetro máximo en su panza, tiene el excepcional interés de estar casi intacto y de haber sido decorado en el mismo taller en el que fue confeccionado, en Lezoux. Presenta el gran motivo central de Mithra sacrificando al toro. A su izquierda aparece un dadóforo con la antorcha levantada; a la derecha, en el lugar que debía ocupar el otro dadóforo, aparece un dios silvestre tañendo una flauta. El conjunto está rodeado por racimos de follaje, dibujados a la barbotina, entre cuyos intervalos se desgranan líneas de puntos, más o menos largas e inclinadas, que producen un efecto ligero y gracioso al conjunto ${ }^{27}$.

23 Vertet, H., Op cit., pág. 122.

24 VERTET, H., Ibidem.

${ }^{25}$ DeCheletTE, J., Vases ornés de la Gaule romain, t. II, pág. 219, núms. 92 y 93.

26 VERTET, H., "Céramique et métallurgie, un nouveau document mithriaque", Revue Archéologique de l'Est et du Centre-Est, t. $X$, págs. 324-332; Idem, Op cit., pág. 123. El núm. 92 se descubrió en Vandée y el núm. 92a, en Londres.

${ }^{27}$ VERTET, H., "Les representations mithriaques sur les vases d'argille en Gauł", págs. 124-125. 
5. ${ }^{\circ}$ Copa completamente decorada a la barbotina, publicada por $\mathrm{J}$. Esperandieu ${ }^{28}$, descubierta en Alesia en el curso de la misma excavación que proporcionó el fragmento referenciado anteriormente por Vertet con el número $1 .^{\circ}$ La arcilla es rosada, rayada con la uña. Su superficie es rojiza, recubierta por un barniz mate tan poco espeso que ha desaparecido en los relieves y en otros puntos. Se ha conservado, no obstante, gran parte de su decoración. Ésta no comprende más que un motivo central representando a Mithra tauróctono entre sus dos habituales acompañantes, Cautes y Cautopates. Su semejanza con el ya mencionado vaso de Lezoux, con el número $4 .^{\circ}$ es curiosa. Seguramente se trata, según Vertet, de productos contemporáneos y aunque no se puede asegurar que hayan sido manufacturados en los mismos talleres, si que ambos han tenido estrechas relaciones. En opinión del autor mencionado, el conjunto, si tenemos en cuenta la destreza que se precisa para moldear la arcilla fluida, tiene un aspecto un poco "caricaturesco": las piernas cruzadas del portador de la antorcha, el inestable equilibrio de la figura, la exagerada longitud del torso de Mithra, son el resultado de un trabajo ejecutado demasiado rápidamente ${ }^{29}$.

6. Molde o matriz de Mithra tauróctono, de Lezoux, que según Vertet, lo más probable es que sirviera para fabricar el relieve que decora el vaso número $4 .{ }^{\circ}$ o.

Más recientemente, en 1986, J. M. Demarolle refiriéndose a esta misma serie dentro de su documentado estudio sobre cerámica y religión en la Galia romana, señala que el culto de Mithra proporciona un ejemplo de religión oriental representado por ciertas producciones cerámicas, aunque éstas sean poco numerosas ya que hasta 1963 no contábamos más que con este repertorio integrado por los seis documentos cerámicos citados, y que aún teniendo en cuenta una veintena de fragmentos cerámicos descubiertos posteriormente, había que pensar que estas cerámicas estaban destinadas a un público muy restringido, si bien admite que ciertamente los nuevos descubrimientos podrían debilitar este tipo de argumentos $^{31}$.

En el mismo trabajo de Vertet al que ya nos hemos referido antes también se aludía a otros documentos hallados en diversos lugares. Por

${ }^{28}$ Esperandieu, J., Op. cit.., 1907, págs. 203-205.

29 VERTET, H., Op. cit., págs. $125-127$ y fig. 6.

so VERTET, H., Op. cit., pág. 127 y fig. 7.

${ }^{31}$ Demarolle, J-M., "Ceramique et religion en Gaul romain", en Aufstieg und Niedergang der Römischen Welt, Band II, 18.1. Berlin. New York, págs. 528-530. 
ejemplo, al fragmento descubierto en Viena (Austria), decorado con un posible dadóforo, según opinión manifestada por Cumont a Esperandieu ${ }^{32}$, aunque no citada por $\mathrm{H}$. Kenner, conservadora del museo en donde la pieza se encontraba ${ }^{33}$; a otro descubierto en Roma, e incluso llegaba a suponer que el fragmento 92 a de Déchelette, localizado en Londres, formaba también parte de un vaso decorado con relieves mitraicos ${ }^{34}$. Para Vertet era, por lo tanto, evidente que otros talleres externos a la Galia habían fabricado relieves mitraicos. Por ejemplo, Tréveris, en donde apareció un medallón moldeado en arcilla representando a un Mithra tauróctono acompañado por Sol, Luna, Cautes, Cautopates, perro, león, serpiente y escorpión ${ }^{35}$.

Entre las piezas fabricadas por estos otros alfares externos destaca Vertet las copas estudiadas por Loeschke, decoradas con cabeza de Aqueloo y los Trabajos de Hércules, de Diana, de Orfeo, de Narciso ${ }^{36}$. Pero, aunque no son, como las copas mitraicas, muy abiertas, su estilo es mucho más bello y se las considera como vaciados de copas de plata ${ }^{37}$.

A R. Turcan se ha debido el estudio y publicación de algunos vasos descubiertos últimamente, sobre todo, en el antiguo territorio galorromano. En 1976 y 1978, respectivamente, ha publicado dos breves trabajos ${ }^{38}$. En el primero de ellos estudia un vaso descubierto en Villeneuve-sur-Lot. Se trata de un ejemplar de $35 \mathrm{~cm}$ de altura, de pasta tostada clara, con engobe blanco micáceo. Tenía tres asas con rebaje. Entre las asas, la panza aparece decorada con el relieve en realce de una gruesa serpiente con una quíntuple ondulación y cuya cabeza se hunde en la cara interna del reborde del vaso. De una parte a otra, la panza presenta otras dos serpientes y varias cabezas humanas vistas de frente y sujetas interiormente con dos corchetes. La decoración del vaso comprende, por lo tanto, un total de tres serpientes y seis cabezas hu-

32 Esperandiu, J., en Vertet, H., Op. cit., pág. 128, núm. 1: «Encore inédit et simplement constitué comme l'une des nôtre, par un dadophore, il m'a été signalé obligeamment par F. Cumont qui l'a vu à Vienne sur un tesson, au séminaire d'arqueologie de l'Université».

33 Vertet, H., Op. cit. pág. 128, núm. 1.

34 VERTET, H., Op. cit. pág. 128 (cfr. núm. 5 de su elenco).

${ }^{35}$ LOESCHCKE, S., Trier Zeitscrift, 1934, pág. 168, núm. ST. 114724, lám. XIX-3; VERTET,

H., Op. cit., pág. 128, núm. 2.

36 LOESCHCKE, S., Op. cit., pág. 168, fig. 34, fig. 35, lám. XV y lám. XVI.

37 VERTET, H., Op. cit., pág. 128, núm. 2.

38 TURCAN, R., "Chronique gallo-romain", Journal of Mithraic Studies, Vol. I núm. 2. London 1976, págs. 196-197; Idem, "Chronique gallo-romain", Journal of Mithraic Studies, Vol. II, núm. 2. London 1978, págs. 181-182. 
manas. El descubrimiento se sitúa en un contexto de cerámicas datables a finales del siglol d.C. ${ }^{39}$.

Turcan refiere que el prof. J-J.Hatt ya habia sugerido a J-F.Garnier que podria tratarse de un vaso mitraico semejante a los que pusieron al descubierto las excavaciones de Colonia, pero que el único ejemplar que ofrece alguna analogía con este vaso de Villeneuve - un fragmento de cerámica grisácea llevando una serpiente a la barbotina sobre la panzano tiene un origen mitraico seguro ${ }^{40}$. Según Turcan, la crátera número 13 está decorada con dos serpientes rampantes sobre las dos asas. $Y$ en el caso del número 36 , la serpiente está enrollada sobre la tapadera de un pyxide ${ }^{41}$. Por ello, "ningún vaso de Colonia es exactamente igual al de Villeneuve-sur-Lot». "Queda por señalar, añade Turcan, que la representación del ofidio bebiendo en la crátera sí que está bien atestiguada en la imaginería mitraica, sobre todo en las grandes estelas ilustrativas de la Tauroctonía - donde la serpiente no simboliza el elemento chtónico, como pensaba (creo que sin razón) F. Cumont» ${ }^{42}$.

No obstante, refiriéndose al lugar en el que apareció este vaso, Turcan señala que hay que tener en cuenta que en Eysses (Excisum) habia destacamentos, vexillationes, de la cohors / Classica y de la cohors A/pinorum (CIL XIII, 922-924), citando al respecto a C. Jullian ${ }^{43}$. La presencia de mitraistas podría explicarse por el establecimiento de una comunidad mitraica en esta localidad, última estación antes de Agen, en la gran via de Bourges a Auch ${ }^{44}$.

En su segundo trabajo, Turcan se refiere a la clasificación tipológica de vasos mitraicos propuesta por $\mathrm{M}$. Amand en una ponencia presentada en el Colloque International d'Archèologie tenu à Rouen du 3 au 5 juillet 1975, conmemorativo del centenario del fallecimiento del abate Cochet ${ }^{45}$. 1977

39 TURCAN, R., "Gallia romain", en Journal of Mithraic Studies, Vol. II, núm. 2. London

40 Turcan, T., Ibidem. Cfr. Ristow, G., Mithras im römischen Köln. Leiden 1974, pág. 21, núms. 30, 34-35, láms. XIV-XV, figs. 15-17; lám. XIX, fig. 22; XX, fig. 24; XXII, fig. 26.

41 TuRcan, R., Ibidem; Ristow, G., Op. cit., pág. 21 y lám. XX, fig. 24.

${ }^{42}$ Turcan, R., "Chronique gallo-romain", Journal of Mithraic Studies, Vol. I núm. 2. London 1976, pág. 196. Cfr. también Rıstow, G., Mithras im römischen Köln, EPRO, 42. Leiden 1974, pág. 21, núms. 13; pág. 30, núms. 35-37, láms XIV-XV, figs. 15-17; XIX, fig. 22; XX, fig. 24; XXII, fig. 26. Para el ejemplar núm. 36 Cfr. pág. 30 ss y lám XX, fig. 24.

${ }_{43}$ Jullian, C., Histoire de la Gaule, IV. Paris 1913, pág. 289, núm. 1.

44 TurCan, R., Op. cit, pág. 196.

45 AMAND, M., "Les vases mithriaques aux serpents dans l'Empire romain", en Le Pèriode Gallo-Romain, Colloque international tenu à Rouan du 3 au 5 juillet, 1975, págs. 165169. 
M. Amand propone una clasificación tipológica en relación con la distribución geográfica de los ejemplares de estos vasos. A la Galia le asigna la tercera y la quinta de las seis categorías establecidas. La tercera categoría (perfil de botella con panza aplastada, largo cuello, labio vuelto, golletes ciegos y moldurados dispuestos en el nacimiento del cuello en torno al cual se enrosca una serpiente), la sitúa concretamente a lo largo de los Valles de l'Escaut y Dendre, en Bélgica. La segunda, en Tournai y en Aardenburgh, en los Ménapiens, en Blicquy y en los Nerviens. Al vaso de Cambrai, conservado en Duai (Museo de Chartreuse), con asas horizontales con serpientes sobre el cuello, y panza decorada con cuatro bustos femeninos la engloba en la quinta categoria. Según M. Amand, la presencia de vasos de este tipo en el curso superior de l'Escaut demostraría que el culto de Mithra estaba implantado en los grandes centros de este valle, desde las fuentes hasta la desembocadura de sus correspondientes ríos ${ }^{46}$.

Pero, según Turcan, esta afirmación debe de ser demostrada ${ }^{47} y$ apela a las opiniones de quienes conocen bien los vasos decorados con serpientes fuera de todo contexto mitraico, especialmente a $G$. y $R$. Heldenbergh ${ }^{48}$. Y aludiendo a la decoración de este vaso, Turcan señala que la serpiente "es con frecuencia un símbolo de la fecundidad, de la salud y de la prosperidad" "49. No obstante, sobre la simbología de la serpiente en la iconografía mitraica, nos remitimos especialmente a un trabajo nuestro, recientemente publicado ${ }^{50}$.

Diez años después de la sistematización de Vertet, aparece el ya citado trabajo de Marcel Amand, cuya finalidad es la de establecer una categoria específica de los vasos decorados con serpientes en todo el Imperio Romano, conocidos hasta entonces con el nombre de vasos con serpientes 0 incluso con el anterior apelativo alemán de "Schlangengefäsze” ${ }^{51}$.

Sobre la base tanto de su iconografia como de la antigua datación - finales del siglo I d. C.- de algunos de sus ejemplares, estos vasos

46 AMAND, M., Op. cit., pág. 167.

47 TURCAN, R., Op. cit., pág. 182: "La chose demande á être verifiée".

${ }^{48}$ Heldenbergh, G y R., Op. cit., pág. 522 y fig. 3,6 en la que vemos tres serpientes aplicadas a la borbotina sobre todo el contorno del cuello.

49 TuRCaN, A., Op. cit., pág. 196.

50 VAZQUEZ HOYS y MUÑOZ J., “Simbología de la serpiente en contextos arqueológicos mitraicos", en Espacio, Tiempo y Forma. Serie II, 3, Historia Antigua. Madrid, UNED, 1990, págs. 85-116. 165-169.

51 AMAND, M., “Des vases mithriaques aux serpents dans l'Empire romain», 1975, págs. 
decorados con serpientes podian atribuirse al culto de Sabazio más que al de Mithra, según algunos investigadores ${ }^{52}$, aunque lo cierto es que la opinión más extendida los atribuye al de Mithra ${ }^{53}$ (fig. 2). En cualquier caso, Amand establece seis tipos de vasos dentro de esta categoría, como luego veremos.

Los vasos clasificados por el mencionado autor proceden de los mitreos de Friedberg, Stockstad, Carnuntum y Pettau, entre otros, lugares en donde no es raro encontrarlos por la existencia de mitreos en ellos. Pero también incluye los procedentes de lugares en los que nunca se ha documentado la existencia de mitreo alguno, especialmente, en las provincias de Retia, Germania Superior y Bélgica II. Se reparten, sobre todo, a lo largo de las fronteras Nordeste y Norte del Imperio, en Neuss (Novaesium), en Bad-Deustch-Altenburg (Carnuntum), con depósitos de concentración más o menos densos al Oeste y al Sur del Rhin, en Bélgica y Suiza, al Sur del Danubio, en Baviera, y al Norte de este último río, en Rumanía, demostrándose así, según Amand, que el culto de Mithra tam-

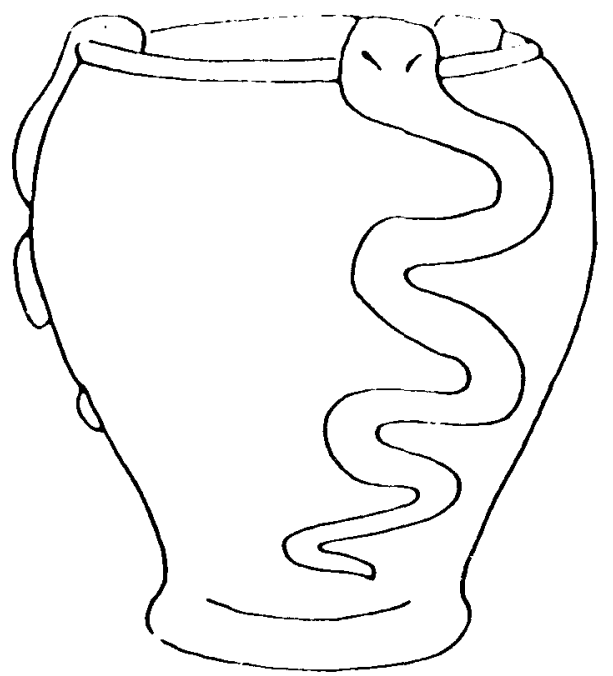

Fig. 2. Vaso en forma de cubilete ovoidal decorado con tres serpientes (AMAND; Tipo C/1 y SWOBODA, Tipo 6).

52 Cfr. esp. Daexel, F., 1912; Staehlin, F., 1948; Ettulinger, 1956.

53 Cumont, F., 1894, y 1896; SWOBOda, 1937; Vermaseren, M. J., 1965; Binsfeld, W., 1960-1961; Ulbert, 1963; Popilian, G.- Bordea-Penaru, 1973. 
bién se había difundido fuera de los centros militares del limes e incluso que se habia diseminado por los campos ${ }^{54}$.

Cuando Amand publica en 1975 este trabajo ya se consideraban notables los ejemplares de vasos que se acababan prácticamente de descubrir al Sur de la Gran Bretaña, en Cirenster, y en la antaño próspera ciudad de Lullingstone, así como la serie de ejemplares hallados a partir de 1958, en Tournai y en Aardenburg, en la antigua ciudad de Mènapiens; desde 1968, en Blicquy, en la también antigua ciudad de los Nervios, y a partir de 1975, en Cambrai, en la ciudad del mismo nombre, en Baviera, descritos por Th. Ulbert ${ }^{55}$, y en Romula Malva, en la Dacia ${ }^{56}$.

Según Amand, el ejemplar de vaso decorado con serpientes cuya relación con el culto de Mithra confiere su sentido a toda esta serie es el descubierto en 1958 en la Zeughausstrasze de Colonia ${ }^{57}$. Se trata de una crátera provista de sendas asas en torno a las cuales se enroscan respectivamente el cuello y la cabeza de una serpiente superpuesta al vaso y sostenidas cada una de ellas por un león echado, y la parte alta de la panza de la crátera decorada con signos astrales con ocho brazos patados, y acabado a la barbotina; realizado en color negruzco, Mithra con sus dadóforos Cautes y Cautopates (Fig. 10,1 y 10,2). Esta crátera, datada por el contexto arqueológico de su hallazgo, a mediados del siglo \| d. C., está por otro lado, provista de $\|$ talón agujereado en su abertura.

Otro ejemplar muy semejante, con la figura de un escorpión superpuesta sobre el reborde del labio, friso pintado con seis estrellas de ocho rayos y representación de Mithra con la cabeza vuelta hacia los cuartos traseros del toro y un ramillete vegetal, procede de un campo de legionarios de Mayence.

Para Amand, una primera categoría es la integrada por las cráteras decoradas con serpientes con dos asas, con o sin friso superpuesto o pintado, como las ya citadas de Colonia y Mayence, provenientes sobre todo del valle del Rhin y del limes, incluyendo también en ella los ejemplares que se han podido reconstruir a partir de los fragmentos descu-

${ }^{54}$ Amand, M., Op. cit, pág. 166.

55 UlBert, TH., "Römische Gefäsze mit Schlange - und Eidechsenauflagen aus Bayern», en Bayerische Vorgeschichtsblätter, XXVIII, 1963, págs. 549-560.

${ }_{56}$ Popillian, G.-Bordea, P., "Date noi provind cultuele de la Romula-Malva in lumina vaselor cu figuri in relief", en Studii si cercetari de Istorie veche, XXIV, 1973, págs. 239257).

AMAND, M., Op, cit., pág. 166. 
biertos en Intercisa-Dunapentele y en Carnuntun-Bad-Deutchsch-Altenburg (fig. 13), en Pannonia ${ }^{58}$. Las serpientes de estas piezas tienen la cabeza coronada por una cresta, un gran ojo abierto, vigilante, las fauces entreabiertas y el buche con la bolsa del veneno claramente marcada.

Una segunda categoria de vasos mitraicos con serpientes es la dotada tanto de asas como de tres falsos golletes. Estos golletes están colocados sobre los lomos de las asas, como en los ejemplares de Augst $y$ de Windish (fig. 3) o entre ellos, como en el ejemplar de Pocking (fig. 4). El hocico de la serpiente asoma sobre el asa en torno a la cual está enrollado el cuerpo del reptil y se apoya sobre el reborde del labio del vaso. La panza se adorna con motivos superpuestos, máscaras apotropaicas en actitud desafiante, como en Pocking; lagartos, como en Augst; mangos con siete brazos, como en Windish ${ }^{59}$.

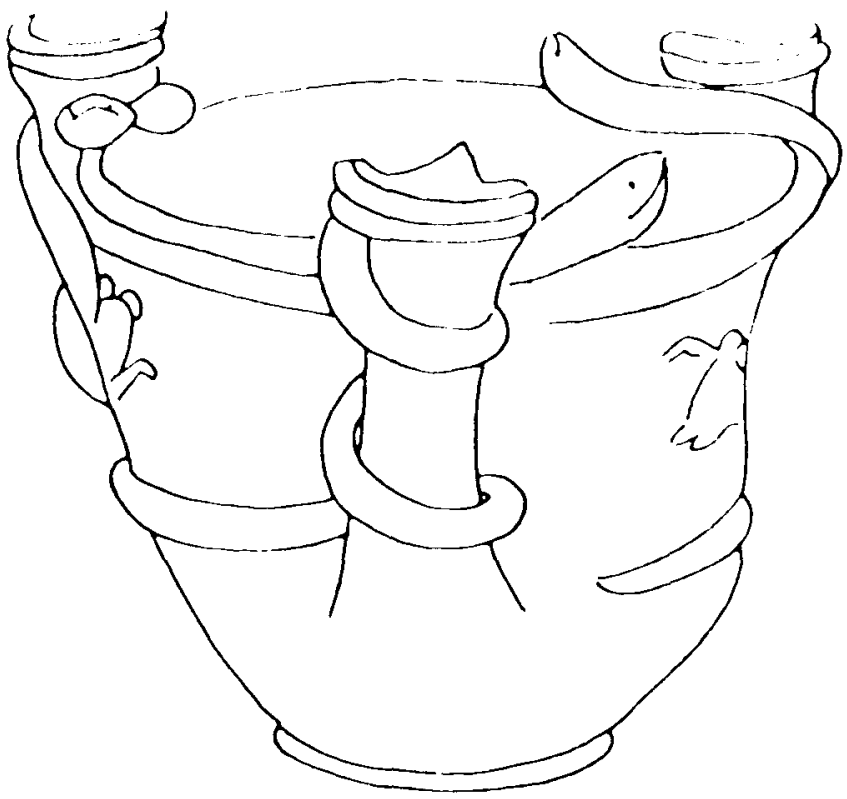

Fig. 3. Crátera de base carenada, con tres asas coronadas por golletes ciegos con serpientes enroscadas (AMAND Tipo C/2-a y SWOBODA, Tipo 1).

58 Amand, M., lbidem.

59 AMAND, M., Ibidem. 


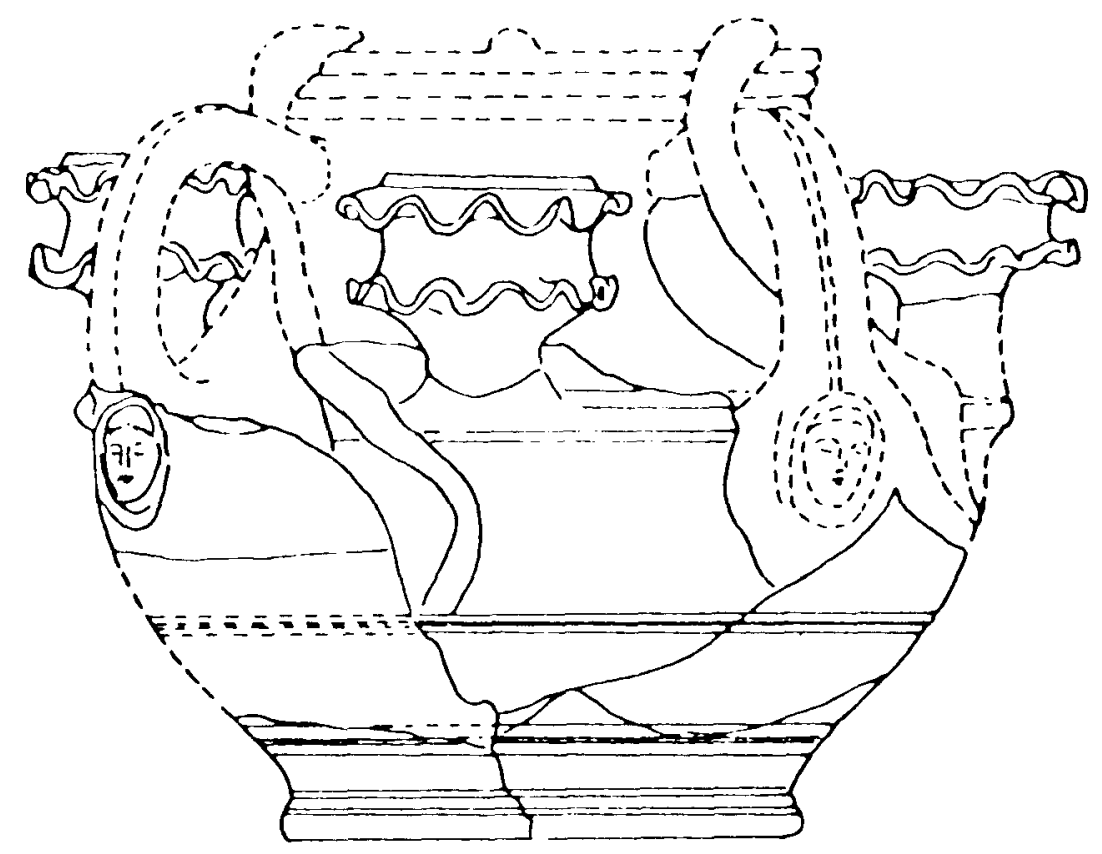

Fig. 4. Crátera de perfil bulboso con tres asas alternadas con tres golletes (AMAND, Tipo C/2-b y SwOBODa, Tipo 1).

La tercera categoría es la que se evidencia a lo largo de los valles de l'Escaut y del Dendre, en la provincia de Bélgica II, en Tournai y en Aardenburg, antigua ciudad de Menapiens, como antes señalamos, y en Blicquy, antigua ciudad de los Nervios, como también dijimos. El perfil de estos vasos recuerda al de las botellas con panza aplastada, con largo cuello y borde abierto, reborde decorado con un festón plástico ${ }^{60}$.

Al menos dos golletes ciegos y moldeados están dispuestos en el nacimiento del cuello en torno al cual se enrosca una serpiente, presentando en cada uno de sus extremos una cabeza con los ojos bien marcados, el cuello apoyado contra el perfil de los golletes, antes de curvarse sobre su reborde, y de introducir el hocico en el interior del vaso (fig. 5). Estos vasos tienen, pues, golletes, pero están desprovistos de asas -algunos de los ejemplares de Tournai muestran trazas de dorado con

¿ Amand, M., Op. cit., pág. 166-167. 


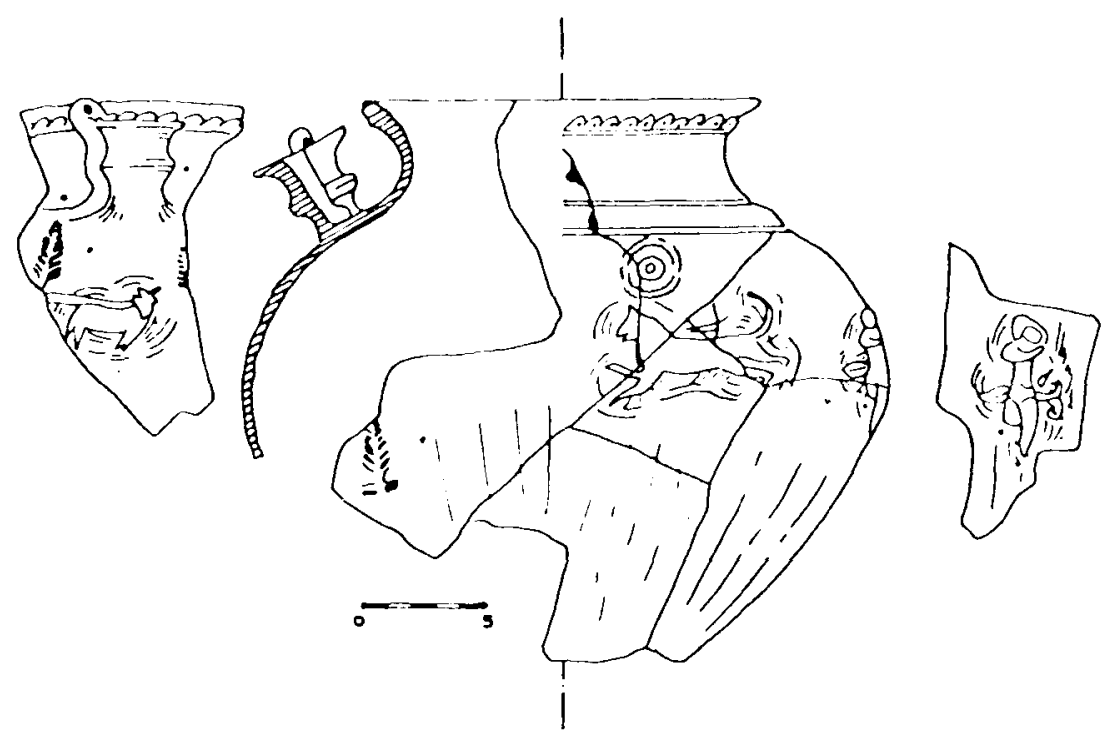

Fig. 5. Vaso de dos golletes, con serpientes y rica decoración estampada e impresa (AMAND, Tipo 3).

mica-; otros están decorados con un friso de motivos estampados e impresos: Bacante, león dextrógiro (vuelto hacia la derecha), gallo dextrógiro, escorpión (?), carnero levógiro (vuelto hacia la izquierda), rosáceas, piñas, impresas sobre el incompleto vaso de Tournai, carnero levógiro y bolsa o saco sobre un gran fragmento de Blicquy ${ }^{61}$.

Amand reconoce que rehuye intencionalmente la interpretación de toda esta compleja iconografía, pero señala que la presencia de gallos, carneros, bolsas, etc., autoriza a suponer que la serie de motivos, que estima en número de ocho, podria haber estado completada con un busto de Mercurio, sin contar otros bustos que se intercalan entre ellos. Mercurio está asociado con frecuencia a la iconografía de los mitreos de Germania y representado a menudo en vasos decorados con bustos, bien conocidos en la región: los vasos llamados de Bavai, que durante mucho tiempo se han estado calificando indebidamente, según también M. Amand, con el nombre de "vasos planetarios", a veces con forma de un tricéfalo, como en los fragmentos de Tournai, en los que un busto

${ }^{61}$ Amand, M., Op. cit., pág. 167. 
muestra una cara imberbe, el torso cubierto por una clámide, a veces en epifanía, con atributos, como sobre el vaso de Montigniers-Saint Christophe ${ }^{62}$.

Según Amand, la presencia de los golletes es el único elemento que impide la incorporación de estos vasos a la serie poco conocida decorada con una serpiente criocéfala, la cual se reconstruye a partir de los fragmentos de Bavai, Blicquy, Tourinnes-Saint-Lambert y Velzeke, sobre los cuales, como en ciertos bajorrelieves, Mercurio está asociado al dios serpiente celta ${ }^{63}$.

Una cuarta categoria, en opinión de Amand, cuyo único ejemplar completo es el del Mitreo de Friedberg, presenta aspecto de caliz con asas (figs. 8.1 y 8.2). Su perfil recuerda el de ciertos cálices para incienso, su panza está decorada con motivos superpuestos con significado cultual: un escorpión y una escala esquemática, la cual se encuentra, en ocasiones, fundida en bronce en sepulturas del siglo iv, en el valle del Rhin (Bonn, Colonia), junto con otros pequeños motivos que Lehner relaciona tanto con el culto de Sabazio como con el de Mithra ${ }^{64}$.

En la quinta categoría incluye Amand el gran vaso de Cambrai (el del Museo de Chartreuse, en Douai), con asas horizontales decoradas con serpientes y otros motivos sobre el cuello, y su panza decorada con cuatro bustos femeninos. Su presencia en el curso superior de l'Escaut constituye, en opinión del autor citado, la prueba de que el culto de Mithra estaba establecido en los centros importantes del valle de este río, desde sus fuentes hasta su desembocadura ${ }^{65}$, opinión, que, como ya hemos señalado, pone en duda Turcan ${ }^{66}$.

La sexta y última categoría de vasos con serpientes conocidos hasta ahora es de un tipo menos elaborado y está formado por cacerolas ovoidales desprovistas de asas y de golletes (fig. 11). Sobre su panza están superpuestas tres serpientes con el hocico apoyado sobre el reborde del labio. Este tipo de vasos se ha descubierto en las sepulturas de la provincia de Rhetia, en el cantón de Valais, en Suiza, en Isérables y en Riddes, en Austria, en Innsbruck-Veldidena. En una breve estudio aparecido en 1919, Sam Wide llamó la atención sobre el tema de la serpien-

62 AMAnd, M., Ibidem.

63 AMAND, M., Ibidem.

${ }_{64}$ Amand, M., lbidem. Cfr. también Ogawa, H., Op cit, págs. 854-873.

${ }_{65}$ AMANo, M., Op. cit., pág. 167.

${ }^{66}$ TURCAN, A., "Chronique gallo-romain", Journal of Mithraic Studies, vol. II, núm. 2. London 1978, pág. 182 
te como simbolo del difunto ${ }^{67}$. Por ello, esta sexta categoría de vasos con serpientes descubiertos en sepulturas y bien localizados podrian revestir cierta significación exclusivamente funeraria de tradición mediterránea y proceder de círculos no sólo externos a los mitraicos ${ }^{68}$, sino muy anteriores a ellos como creemos ${ }^{69}$.

En cuanto a la decoración con serpientes, destaca, en el caso concreto de vasos mitraicos, las cráteras y los kernoi, de diversos tipos. Aunque su presencia pueda sorprender en la antigua Bélgica II, existen otros documentos no menos importantes - los relieves en bronce de Angleur, en el Museo Arqueológico de Lieja, las inscripciones de Theux y de Julensville, en la antigua ciudad de Tongres- que demuestran que el culto de Mithra tampoco era desconocido en esos lugares ${ }^{70}$.

Desgraciadamente no es posible, según Amand, asignar una fecha precisa a los fragmentos cerámicos de Tournai, de Blicquy, de Aardenburg y de Cambrai. Los de Tournai y Blicquy se han fabricado en el mismo lugar que los vasos con bustos de divinidades planetarias, lo que permitiría formularse la preguna de qué afinidades pudieron haber tenido con los vasos mitraicos ${ }^{71}$.

Toda esta documentación arqueológica sobre vasos litúrgicos tanto de un carácter mitraico seguro, como sobre aquellos otros cuya atribución mitraica resulta más difícil o imposible, así como, sobre todo, los que presentan una clara o dudosa identificación con otras divinidades ha quedado integrada recientemente en el nuevo trabajo que Marcel Amand ha dedicado al estudio prácticamente exhaustivo de los vasos decorados con bustos, con representaciones zoomorfas y con serpientes, descubiertos en los territorios de las antiguas provincias de Bélgica y de Germania $^{72}$. La segunda parte de esta misma obra la constituye un Corpus en el que el citado autor recoge casi todo el material conocido hasta la fecha e incluso el inédito. El conjunto de documentos examinados es tan extenso y variado que las conclusiones a las que llega Amand descansan en bases tan sólidas que, en su opinión, «ningún nuevo descu-

${ }^{67}$ Wide, S., 1919, en Amand, M., Op. cit, págs. 167-168

68 Küster, E., Op. cit, págs. 1 ss.

${ }^{69}$ Cfr. Vazouez, A. M., y Muñoz, J., Op. cit., págs. 85-116.

70 Amand, M., Op. cit., pág. 168.

71 AMAND, M., Op. cit., pág. 168.

72 AMAND, M., Vases à bustes á decor zoomorphe et vases cultueles aux serpents dans les anciennes provinces de Belgique et de Germanie, Acádemie Royale de Belgique. Mém. Beaux Arts, t. XV. fas. 2. Bruxelles 1984. 
brimiento podria alterarlas» ${ }^{73}$. Y esto, por lo tanto, es también válido para las conclusiones referentes al mitraismo, materia a la que ya había dedicado el trabajo analizado por nosotros anteriormente.

El territorio seleccionado por Amand como objeto de estudio corresponde, como decimos, a las antiguas provincias de Bélgica y de Germania, es decir, a la región limitada al Este por el Rhin; al Sur por una línea imaginaria que iria desde las fuentes del Mosela y del Meuse, pasando al Sur de Grand, de Chalons-sur-Marne, de Chateau-Thierry y de Senlis, hasta la Mancha al Oeste, entre el Sena y el Somme.

Bélgica y Germania formaron, como es sabido, un sólo territorio desde su conquista por Roma. Y la creación de Germania Inferior y Superior como provincias imperiales consulares, separadas de Bélgica, data del reinado de Domiciano (año 83 u 89).

Dado el interés de los vasos cultuales decorados con serpientes, Amand hace extensivo su estudio a los descubiertos en Campos Decumanos, en la Retia, en la Nórica, en las dos Pannonias y en la Dacia. De aquí también el interés de esta nueva investigación.

Tres son los tipos de vasos del Corpus general elaborado por Amand ${ }^{74}$ :

- Tipo A) Vasos decorados con bustos (en esta definición engloba las denominaciones tradicionales de vasos planetarios, jupillianos, de Bavay, vasos con caras o máscaras apotropaicas).

- Tipo B) Vasos con decoración zoomorfa, que, además, también presentan bustos $y$ otros diversos atributos.

- Tipo C) Vasos cultuales decorados con serpientes, denominación con la que'transcribe el término tradicionalmente aplicado a estos ejemplares en publicaciones alemanas, ya sean cráteras, cántaros, urnas.

El procedimiento más frecuente empleado para la confección de los bustos decorativos consistía, según Amand, en aplicar un molde sobre la panza del vaso antes de su cochura y empujar desde el interior la pasta fresca con un mazo de madera o simplemente con los dedos contra dicho molde, lográndose así una decoración estampada. Un segundo pro-

73 Amand, M., Op. cit., págs. 11-12.

74 AMAND, M., Op. cit., págs. 17-18. 
cedimiento, que entronca con el del relieve aplicado, consiste, según el citado autor, en confeccionar por separado las figuras antes de ser aplicadas sobre la pared del vaso, poniendo en ella un pegote de arcilla destinado a ocultar su unión ${ }^{75}$.

Por otra parte, Amand divide el Corpus en tres partes, constituidas por los siguientes territorios ${ }^{76}$ :

- Bélgica-Holanda (Países Bajos)

- República Federal Alemana

- Francia

En cada uno de estos países, los documentos se han clasificado por orden alfabético de acuerdo con la inicial del nombre de su lugar de descubrimiento, lo cual facilita, sin duda, su localizaciòn inmediata ${ }^{77}$.

Centrándonos nosotros en todos los posibles vasos litúrgicos mitraicos incluidos en dicho Corpus, hemos comprobado que la mayor parte de ellos corresponde al «Tipo C) Vasos cultuales con serpientes". Pero hemos de adelantar que esto no quiere decir que no existan vasos litúrgicos mitraicos que no puedan incluirse en los otros dos grupos, es decir, en el «A)» $y$ en el «B)», $y$ de insistir, una vez más, en que tampoco todos los vasos decorados con serpientes son mitraicos. En nuestra opinión, en todo el Corpus de Amand subyace el problema del sincretismo, dificultando la atribución de muchos de estos documentos al culto de Miithra. Señalaremos, como ejemplo más notable, la evidente dedicación de algunos de estos vasos, clasificados como «no mitraicos», a Mercurio. No podemos discutirlo ¿Pero acaso el sincretismo entre Mithra y Mercurio no se manifiesta en innumerables contextos arqueológicos mitraicos a lo largo de todo el Imperio? En la propia Hispania ¿no tenemos una de las mejores muestras de este sincretismo en la representación escultórica del Mercurio sedente del Mitreo de Augusta Emerita? ${ }^{78}$ (fig. 14).

Por otra parte, de admitirse este mismo sincretismo para los vasos de las regiones antes citadas, la extensión del culto mitraico en ellas sería tan copiosa como sugiere Amand ${ }^{79}$, y pone en duda Turcan ${ }^{80}$.

75 AMAND, M., Op. cit., págs. 14-15.

${ }^{76}$ AMAND. M., Op. cit., págs. 111, 206 y 218.

77 AMAND, M., Op. cit., pág. 18.

${ }^{78}$ Melida, J.J., "Cultos emeritenses de Serapis y de Mithras", Boletín de la Real Academia de la Historia, t. LXIV-cuad. IV (abril, 1914), págs. 453-454, lám. VII, 1 y 2; GARCIA Y Bellido. A., "El culto de Mithras en la Península Ibérica", en Boletín de la Real Academia de la Historia, t. CXXII, cuad. 1 (enero-marzo, 1948), págs. 337-339, lám. 11, fig. 13.

79 AmAND, M., Op. cit., pág. 167.

${ }^{80}$ TURCAN, A., "Chronique gallo-romain", Journal of Mithraic Studies, Vol II, núm. 2. London 1978, pág. 182. 
De todos modos, los bajorrelieves y mosaicos de los mitreos nos muestran frecuentemente representaciones de vasos litúrgicos, sobre todo, cráteras, flanqueadas o no por una serpiente y un león, es decir, integrando el famoso grupo iconográfico trinario establecido por Will, como señalamos. $Y$ también se conocen algunos raros recipientes de bronce o de mármol utilizados, con seguridad, en las ceremonias del culto mitraico.

M. Amand, identifica por to menos dos talleres especializados en sigillata -el de Lezoux y el de Trier-, que en su opinión, han fabricado cerámicas litúrgicas mitraicas, aunque en pequeña cantidad, ya se trate de platos con representaciones miniaturizadas de las escenas figuradas tomadas de los grandes relieves de los mitreos - Mithra tauróctono, Banquetes entre Mithra y Sol, etc.- o de botellas de cuello estrecho en las que Mithra y sus acólitos aparecen situados en un entorno decorado con frutas y hojas ${ }^{81}$. J.M. Demarolle en el estudio antes citado también destaca la existencia del ya mencionado vaso de Lezoux con decoración completa a la barbotina, representando la imagen de un Mithra tauróctono, que muestra, dice, el paralelismo de decoración existente con las figuras de los bajorrelieves mitraicos, de ciertos mangos de puñales de sacrificio también mitraicos y de la cerámica de tierra cocida. Los soportes pueden diferir, pero la disposición de la escena se mantiene idéntica aún en el caso de uno de estos vasos litúrgicos mitraicos de Lezoux que presenta lo que esta autora considera una "aberración iconográfica", concretamente el hecho de que uno de los portadores de la antorcha la tenga levantada en lugar de tenerla apuntada hacia el suelo ${ }^{82}$, cosa que ya habia señalado anteriormente L.A. Campbell ${ }^{83}$. Igualmente $S$. Loeschke ${ }^{84}$ y luego Demarolle destacan el hecho de que en Tréveris también se fabricaron relieves de tierra cocida con la escena de la Tauroctonia ${ }^{85}$.

Tampoco la producción de los vasos litúrgicos mitraicos se limitaba a los talleres de sigillata. En Castor, en la provincia de Bretaña, por ejemplo, se fabricaron grandes vasos troncocónicos de tierra blanca y barniz grisáceo del tipo GOSE 191, cuya panza estaba decorada en toda su altura con figuras de divinidades en pie, destacándose intencionalmen-

81 AMAND, M., Op. cit., pág. 39.

${ }^{82}$ Demarolle, J-M., Op. cit, pág. 529

83 CambelL, L.A., Mithraic Iconography and Ideology, EPRO, 11. Leiden 1968, págs. 3031 y 81 ss.

${ }_{84}$ LOECHKE, S., Op. cit., 11 (1936), pág. 225, núm. III D, fig. 17.

${ }^{85}$ Demarolle, J-M., Op. cit., págs. 528-529. 
te una de ellas - un unicum-, como ocurre también en los ejemplares hallados en Verulan-St-Albans, fechados a principios del siglo II. En ellos se representa a Mithra y, a su izquierda, a Mercurio ${ }^{86}$.

Pero, en cualquier caso, ha sido la tercera categoría de vasos litúrgicos, fabricados en una cerámica menos fina, la que más se ha difundido, ya que, como hemos comprobado, ha proporcionado ejemplares desde el valle del Danubio hasta el de l'Escaut. A esta categoria es precisamente a la que se ha atenido Amand al confeccionar su Corpus, integrando en ella los siguientes subtipos relacionados con la tipología establecida anteriormente por Swoboda para vasos decorados con serpientes ${ }^{87}$ :

- Tipo C/1: Vasos con forma de cubilete, decorados con tres serpientes (SWOBODA, tipo 6) (fig. 2).

- Tipo C/2: Vasos cultuales con serpientes, con forma de crátera, con tres asas y tres golletes (SWOBODA, Tipo 1) (Figs. 3 y 4).

- Tipo C/3:Vasos con dos golletes, decorados con serpientes, y rica decoración estampada e impresa (fig. 5).

- Tipo C/4: Cráteras con tres asas, decoradas con tres serpientes (SWOBODA, tipo 2) (Fig. 6).

- Tipo C/5: Cántaros con dos asas, con serpientes y otros motivos decorativos (SwOBODA, Tipo 3) (figs. 7, 8.1 y 8.2, 9, 10,1 y 10,2).

- Tipo C/6: Vasos sin asas ni golletes, decorados con motivos zoomorfos (fig. 11).

- Tipo C/7: Gran vaso con asa, de alto cuello cilíndrico y rica decoración (fig. 12).

Ha sido, pues, M. Amand quien, de manera más exhaustiva y precisa, se ha ocupado de clasificar los posibles vasos litúrgicos mitraicos no sólo en su ya mencionada ponencia de 1975, sino también dentro de su más reciente Corpus de 1984 de vasos decorados con bustos y serpientes de estos territorios, y retrocediendo hasta cierto punto a la antigua tipología de Swoboda (excluyendo su Tipo 8 por no existir más que un ejemplar y haber desaparecido).

\footnotetext{
86 Amand, A., Op. cit, pág. 40.

87 Amand, A., Op. cit., págs. 40-56.
} 


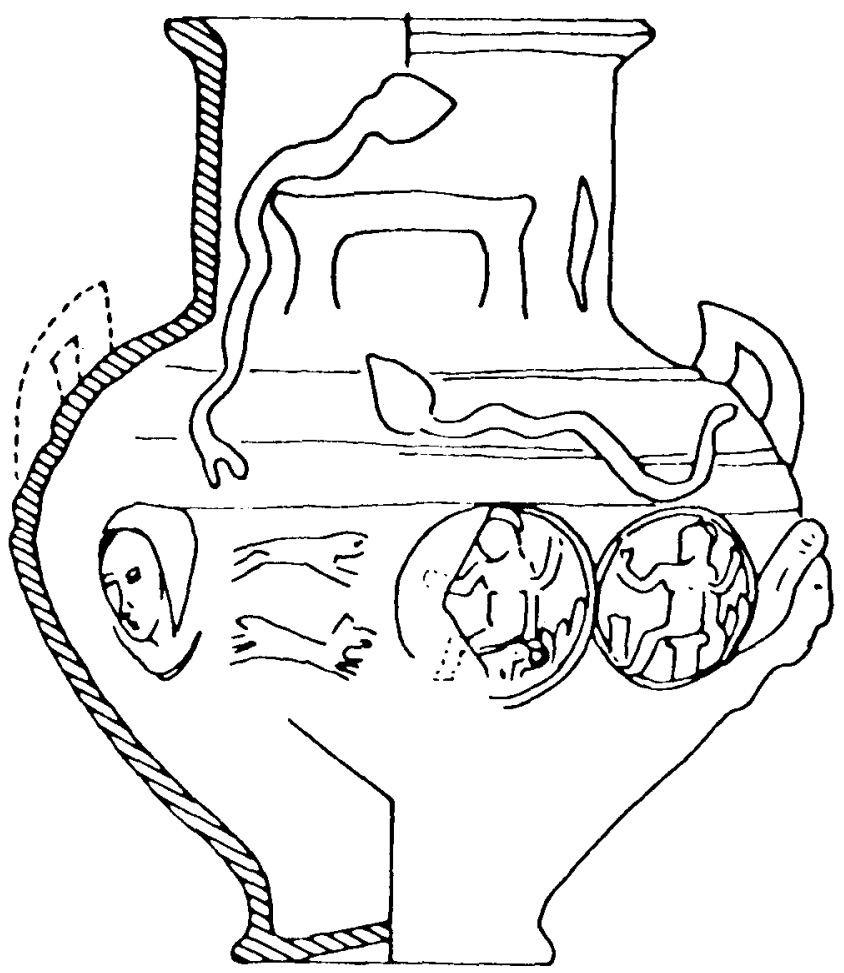

Fig. 6. Crátera de tres asas y tres serpientes en forma de botella (AMAND, Tipo C/4-b y SWOBODA, Tipo 2).

Con anterioridad, aunque no de forma sistemática, algunos de estos ejemplares también habían sido ya incluidos y estudiados por primera vez por $F$. Cumont en su monumental y conocida obra publicada en 1866$1899^{88}$, y posteriormente por M. J. Vermaseren, en su Corpus de monumentos mitraicos ${ }^{89}$. De manera aislada, algunos autores han estudiado otros vasos rituales aparecidos en diversos contextos arqueológicos mitraicos, incluyéndolos (no sistemáticamente) en la relación general de

${ }^{86}$ Cumont, F., Textes et monuments figurés relatifs aux mystères de Mithra, t. I (1899) y t. It (1896), Bruxelles.

89 Vermaseren, M. J., Corpus inscriptionum et monumentorum religionis mithriacae, I y II. La Hague Comitis, 1956-1960. 


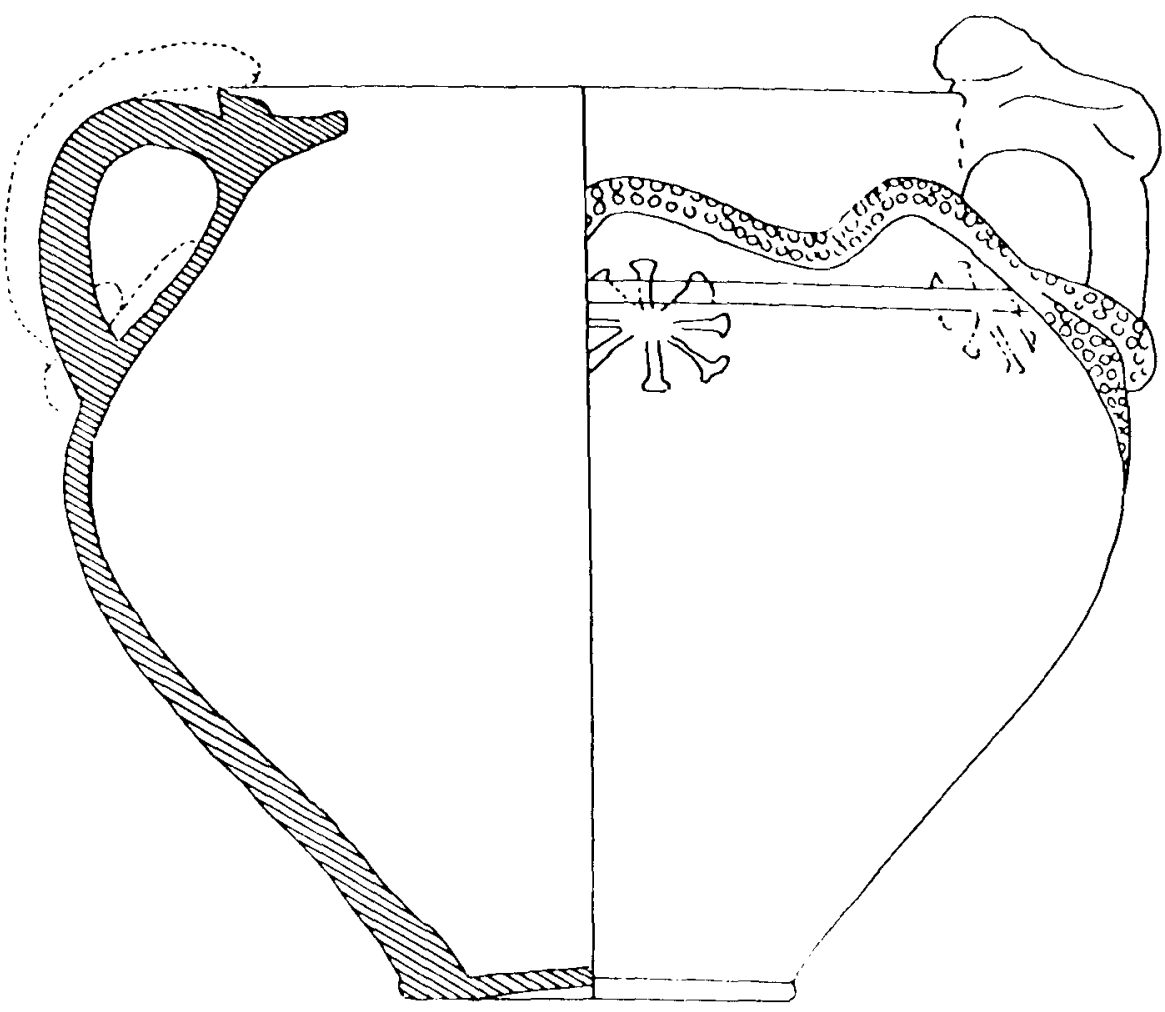

Fig. 7. Cántaro de grandes dimensiones con panza bulbosa, dos asas, dos serpientes y decoración de estrellas patadas (AMAND, Tipo C/5-a y SwOBODA, Tipo 3).

testimonios de este culto descubiertos en los mismos. En este sentido, hay que citar el estudio del vaso aparecido en el Mitreo de Santa Prisca, efectuado por M. J. Vermaseren y por C. C. Van Essen ${ }^{90}$ y posteriormente por algunos otros autores, sobre todo, por Guarducci, autores que

90 Vermaseren, M. J., y VAN Essen, CC., Op. cit., págs. 145-147. Cfr. también las posiciones enfrentadas de VolgrafF, W., ( Une incripción gravée sur un vase cultuel mithriaque", en Med. Kon. Ak. Wet. (N. R., 18.8), 1955, págs. 205 ss) y de EGGER, R., ("Bescheidene Exvotos", en B. J., 158, págs. 73 ss.). 


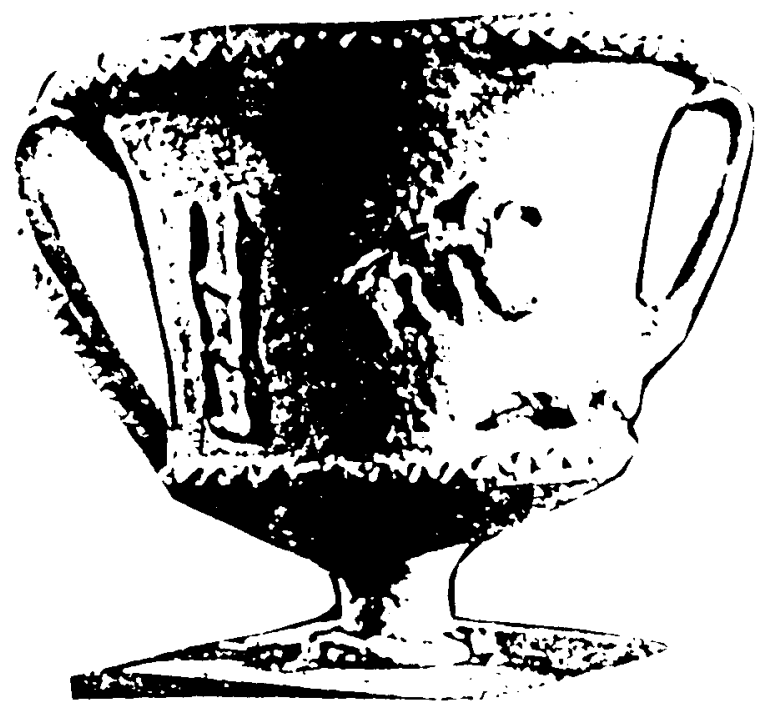

Fig. 8.1. Carquesio de Friedberg de dos asas, con serpientes y otros motivos decorativos (AMAND, Tipo C/5-c y SWOBODA, Tipo 3).

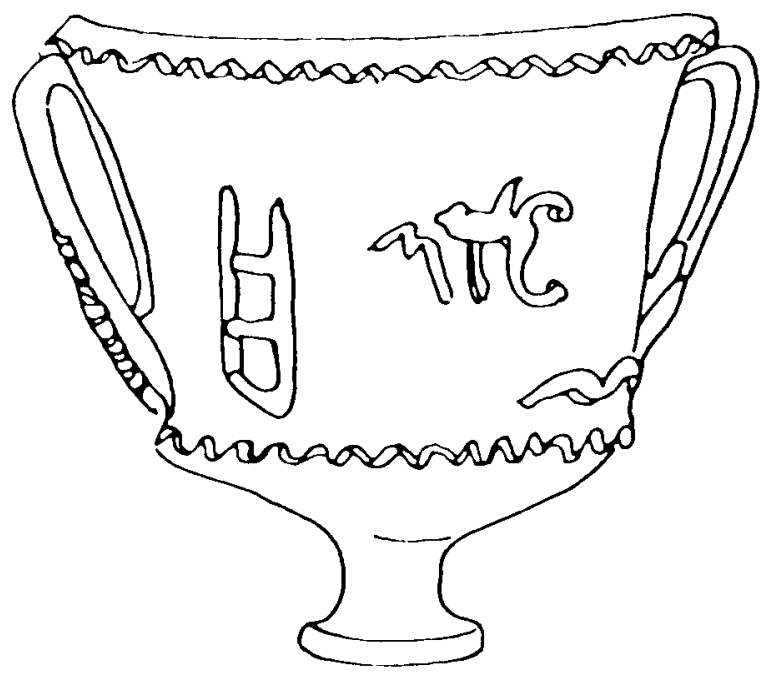

Fig. 8.2. Carquesio de Friedberg (Dibujo de sus elementos iconográficos decorativos: serpientes, escorpión y escala). 


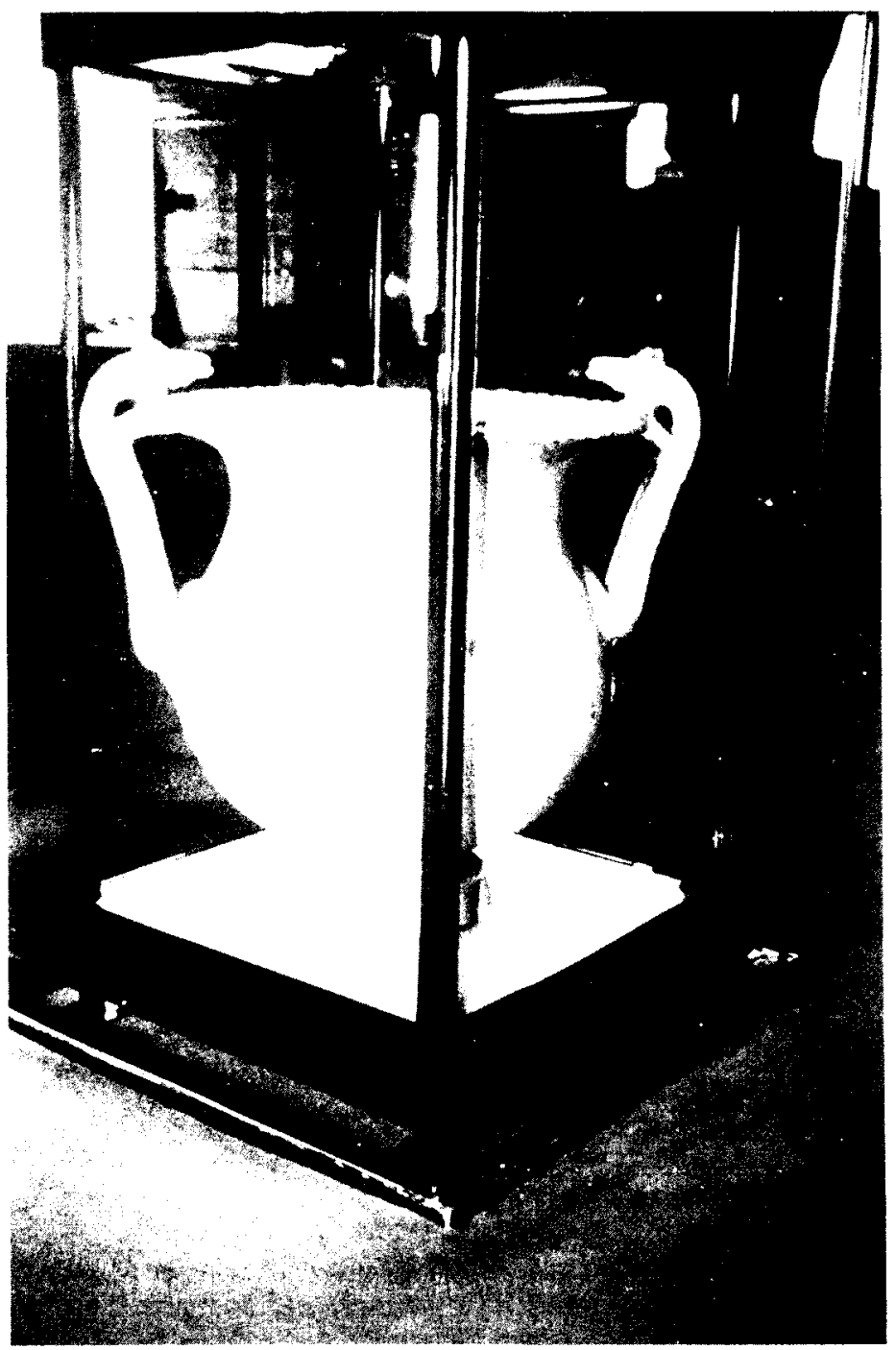

Fig. 9. Vaso de dos asas (reconstrucción a partir de fragmentos). Borde festoneado, serpientes con penacho o cresta sobre las asas y enroscadas en el arranque de las mismas (Amand, Tipo C/5-a y Swoboda, tipo 3). Museo de Colonia (Núm. Invent. 58.200). Foto: A. M. ${ }^{a}$ Vázquez. 


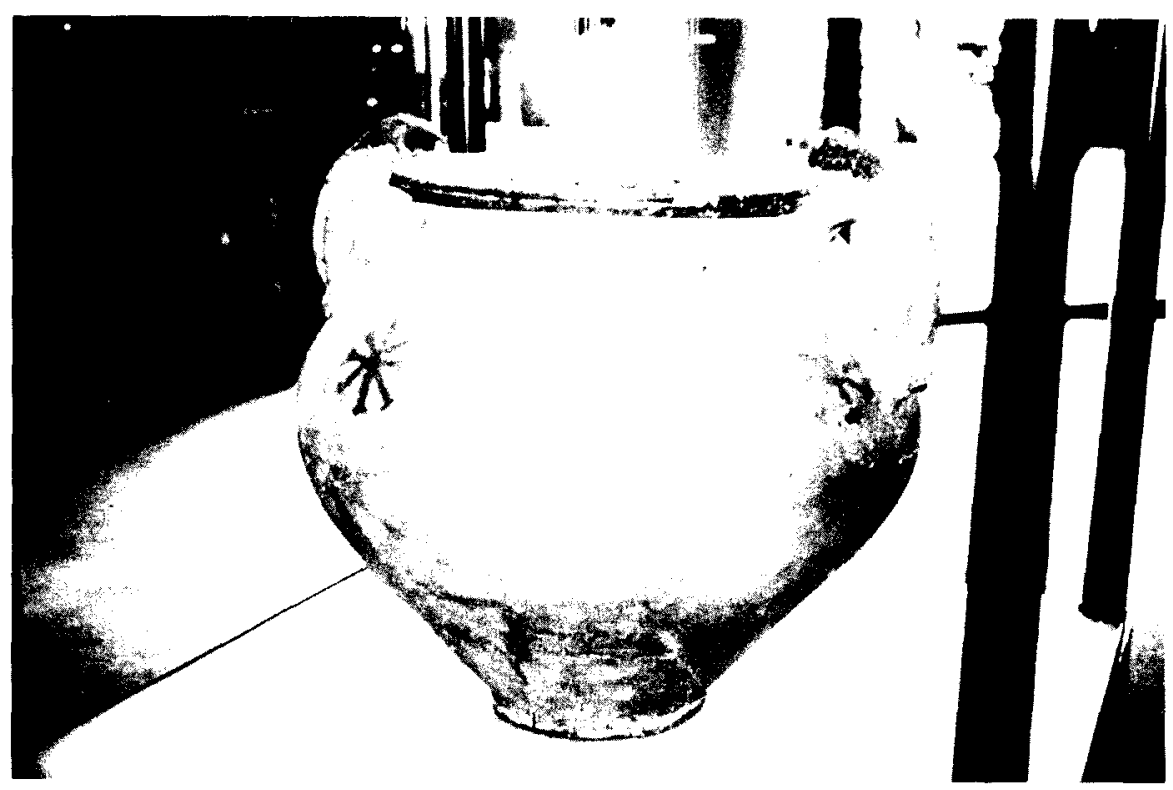

Fig. 10. Cántaro de dos asas, provisto de talón interior, con serpiente y león sobre las asas, respectivamente; relieve de Mithra entre Cautes y Cautopates $y$ estrellas patadas sobre la panza (AMAND, tipo C/5-b, SwoBoDA, Tipo 5). Museo de Colonia (Núm. Invent. 58.289). Foto: A. M. ${ }^{a}$ Vázquez.

han centrado específicamente su atención en los grafitti que presenta este ejemplar ${ }^{91}$.

En España, hasta el momento no se ha efectuado ningún estudio al respecto con excepción de las piezas que nosotros últimamente hemos seleccionado para su análisis en el ya mencionado artículo, en prensa, especialmente centrado en el estudio de la serpiente como elemento iconográfico del culto de esta divinidad ${ }^{92}$.

Aunque la forma de todos estos vasos litúrgicos es diferente, sus características son, en general, muy parecidas. Se trata de grandes va-

91 Guarduccl, M., "Sull' iscrizioni di un vaso rituale del Mitreo di S. Prisca", Mysteria Mithrae. Leiden 1979, págs. 193-194, fig. 1 y 2.

92 Vazouez Hoys, A. M. y Muñoz, J., Op. cit., págs. 85-116. 


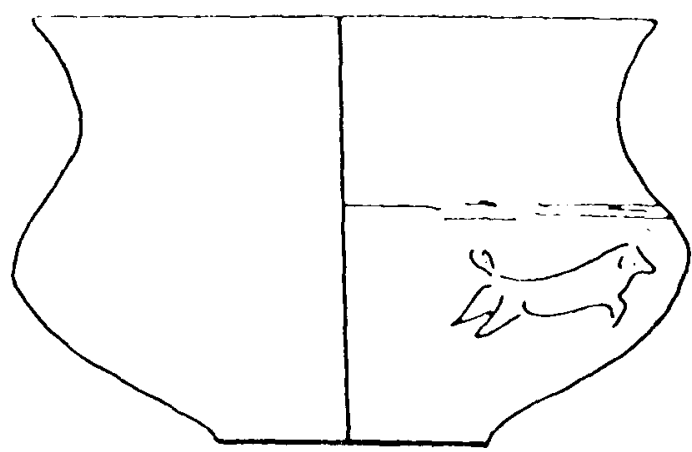

Fig. 11. Vaso sin asas ni golletes, decorado con motivos zoomorfos (AMAND, Tipo C/6).

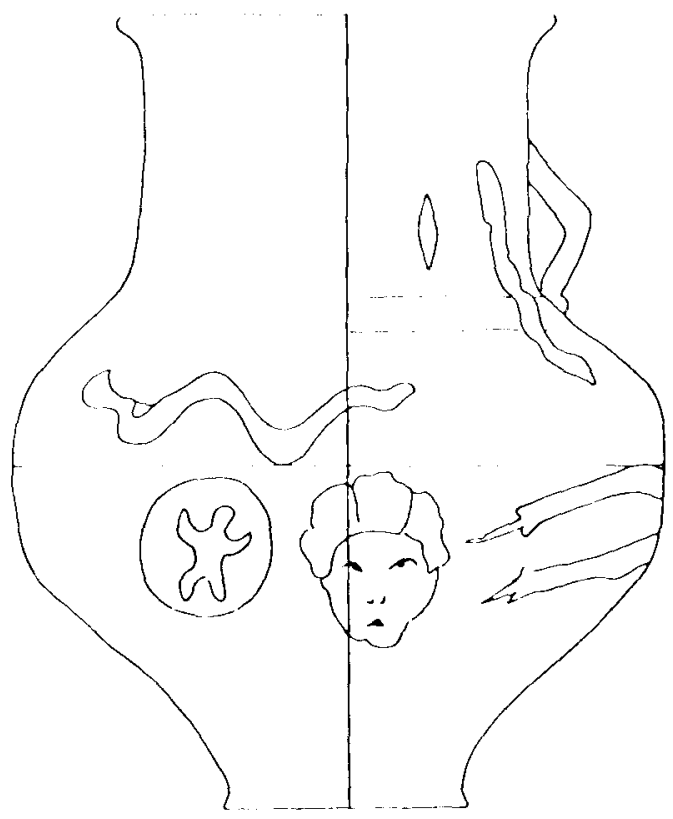

Fig. 12. Gran vaso con asas, cuello alto cilindrico y rica decoración (AMAND, Tipo (7). Su perfil es muy semejante al de la Crátera de tres asas y tres serpientes en forma de botella (AmAND, Tipo C/4 y SwoBoda, Tipo 2). 


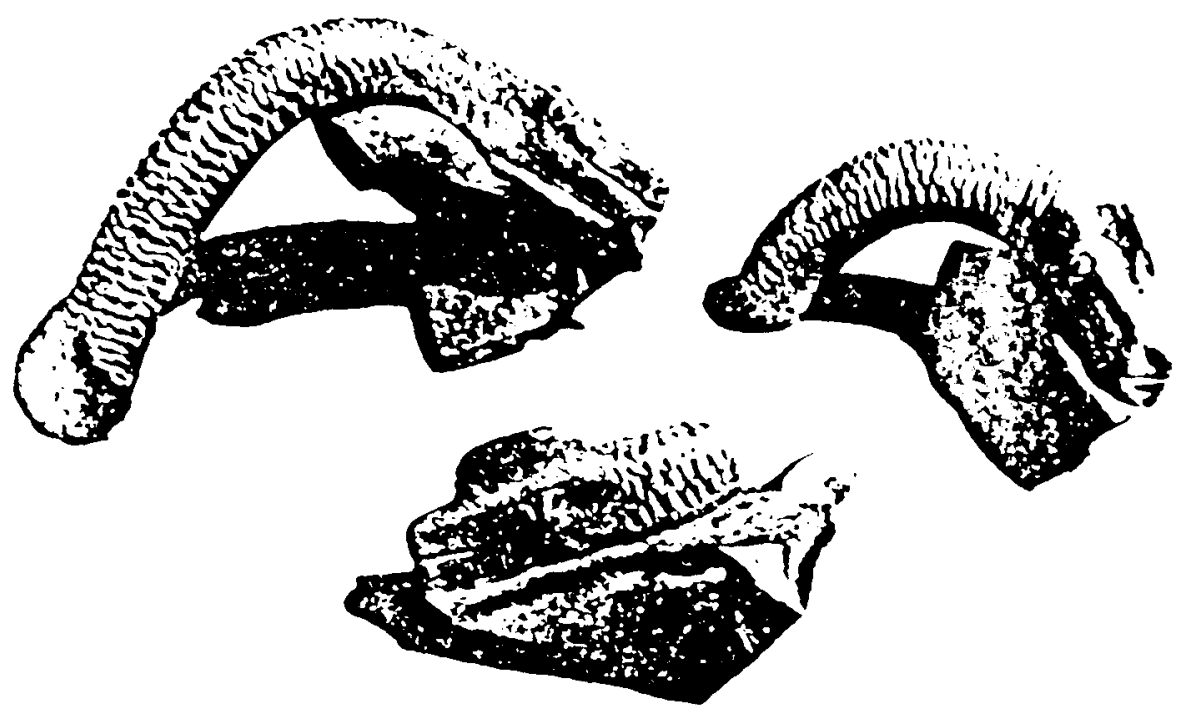

Fig. 13. Fragmentos de un vaso ritual descubiertos en el Mitreo de Carnuntum (Amand, Tipo C/5-a y Swoboda, Tipo 3). Foto H. Kral.

sos, de color parduzco, decorados a la barbotina. Como antes señalamos, su decoración incluye tanto elementos iconográficos mitraicos tradicionales, tales como los conocidos dadóforos Cautes y Cautopates, como otros menos conocidos o desconocidos por completo.

En nuestro país faltan investigaciones sistemáticas sobre la existencia de vasos litúrgicos mitraicos, existencia que nosotros damos por segura teniendo en cuenta la importancia que, como hemos demostrado en algunos de nuestros trabajos, alcanzó este culto en la Península lbérica ${ }^{93}$. Más todavia cuando, en nuestra opinión, ya contamos con cuatro testimonios arqueológicos muy seguros de indudable valor en este sentido.

${ }_{93}$ MuÑoz, J., El culto a Mithra en la Hispania romana. Caracteres especificos (Tesis Doctoral, inédita), UNED, Madrid, 1989; Idem, “Evidencias mercantiles en contextos arqueológicos mitraicos", en Espacio, Tiempo, y Forma, Serie II, 2 Historia Antigua. Madrid 1989, págs. 153-170; Idem, "Vías de difusión de los Sacra Mithrae en la Península Ibérica", en Formas de difusión de las religiones antiguas (Actas del II Encuentro-Coloquio de ARYS, en Jarandilla de la Vera (Cáceres), 17-19 diciembre 1990). Madrid (en prensa); Idem (Conjuntamente con VazouEz Hors, A. M., "Simbolismo de la serpiente en contextos arqueológicos mitraicos", en Espacio, Tiempo y Forma, Serie II, 3, Historia Antigua. Madrid, UNED, 1990. 


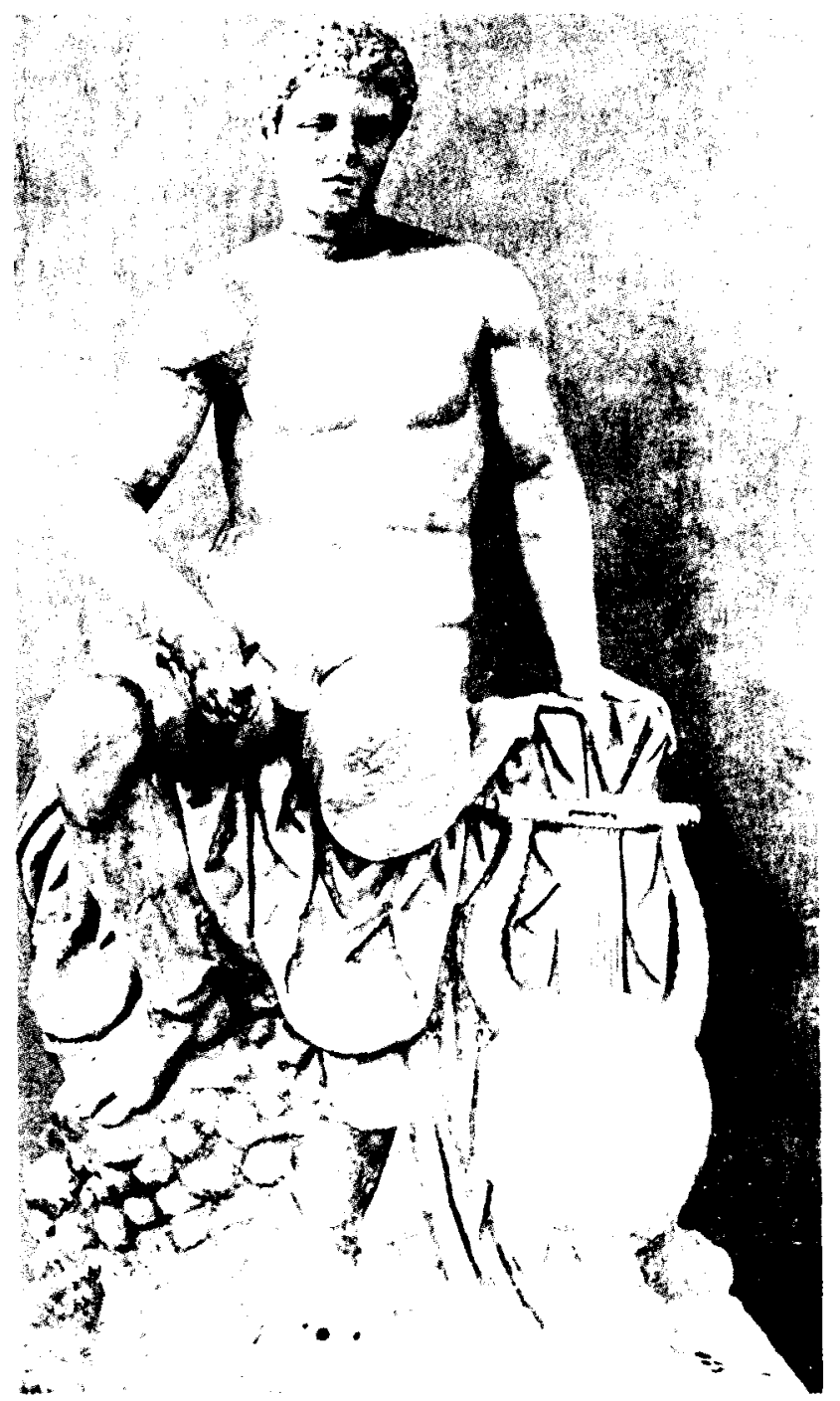

Fig. 14. Estatua de Mercurio sedente del Mitreo de Emerita Augusta. Museo Nacional de Arte Romano de Mérida (Núm. Invent. 508). Foto Mélida. 
El primero de ellos está constituido por los fragmentos de una pátera de ónix, decorada con una serpiente en alto relieve, descubiertos en el yacimiento romano-medieval de Can Madolell, yacimiento en el que coexisten unas estructuras cultuales con otras propias de una explotación agrícola, situado dentro del área rural que configura el territorio de la antigua Iluro, Cabrera de Mar, en la costa tarraconense. Estos fragmentos ingresaron en el Inventario del Museu Comarcal del Maresme, Mataró, con el número 50.395 y han sido, recientemente, objeto de estudio y publicación dentro de los trabajos dedicados a este yacimiento y a sus testimonios arqueológicos ${ }^{94}$ (fig.15).
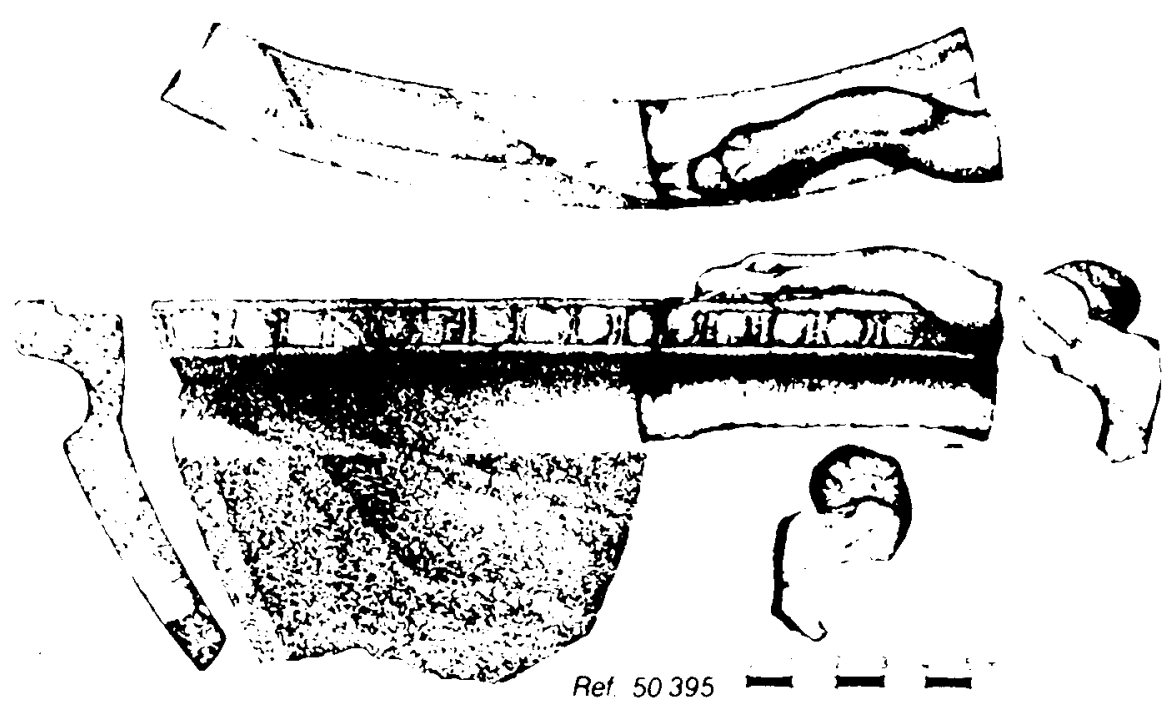

Fig. 15 Fragmentos de una crátera de onix decorada con una serpiente, descubiertos en un contexto de culto mitraico del yacimiento de Can Madolell (Bonamusa, J., et al. (Con dibujos de J. Arenas, J-F. Clariana y E. Juhé): "El jaciment romano-medieval de Can Madolell, Deu anys d'excavacions. Cabrera de Mar. El Maresme (1974-1984)", Mataró, 1985, fig. 12. en pág. 29). Museu Comarcal del Maresme-Mataró (Núm. de Invent. 50395).

94 BonamusA, J., “Els testimonis mitraics iluronesos dins el contex de la Tarraconense" (Ponencia presentada en la $1 .{ }^{a}$ Sessió d'Estudis Mataronins, 17 de marzo, 1984); Laietania, 2-3 (1982-1983), Museu Comarcal del Maresme, Mataró, (1982-83), págs. 248-253; idem, 1985a; idem, 1985b; Bonamusa, J., et al., El jaciment romano-medieval de Can Madolell, Deu anys d'excavacions. Cabrera de Mar. El Maresme (1974-1984). Mataró, 1985, págs. 26-31). 
Es obvio, como venimos sosteniendo, que la mera representación de una serpiente en estos fragmentos no es indicio suficiente para sustentar su posible carácter litúrgico mitraico; pero sí lo es el hecho de que el hallazgo al que nos estamos refiriendo se haya efectuado en un contexto arqueológico de indudable culto mitraico, identificado incluso por sus investigadores con un mitreo dotado de criptopórtico, con cronologia de finales del siglo $\|$ o comienzos del $11{ }^{95}$.

Por otro lado, la aparición de los fragmentos de este vaso litúrgico mitraico en el yacimiento citado refuerza especialmente, en nuestra opinión, no sólo la hipótesis de la existencia de culto mitraico en este lugar, basada, sobre todo, en el descubrimiento de un árula dedicada a Cautopates ${ }^{96}$, sino incluso la del posible mitreo dotado de criptopórtico sostenida por sus descubridores.

El segundo testimonio, prácticamente inédito hasta la fecha, lo constituye un vaso decorado con serpientes descubierto recientemente en Lugo (Lucus Augusti) en un solar de la Calle Armañá número 4, "La Batalla", roto en una canaleta de desagüe. Se trata de un vaso cuyas medidas son $26,6 \times 33 \mathrm{~m}$ (figs. 16,1 y 16,2 ). No obstante, las referencias

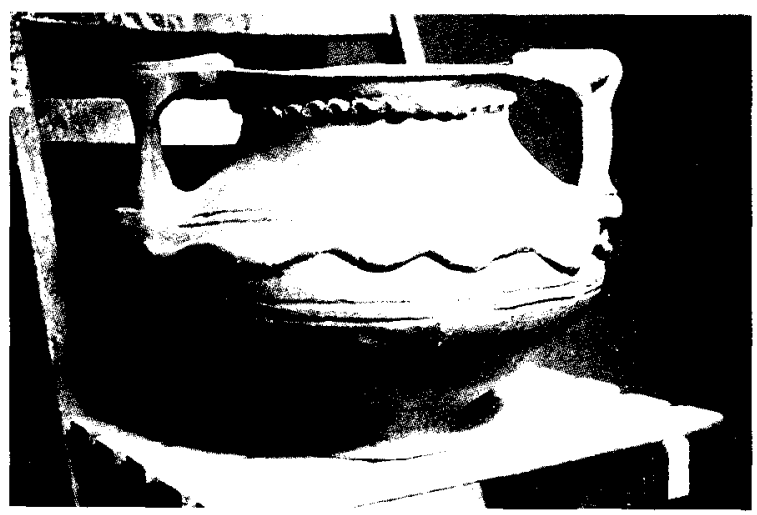

Fig. 16.1 Vaso descubierto en Lugo por el Sr. Algorta Irastorza en el curso de recientes excavaciones. Foto: A. M. ${ }^{a}$ Vázquez.

95 Bonamusa, J., et al., págs. 21 y 61 ).

${ }^{96}$ Mariner, S., 1978: 79-84; idem, "Nuevos testimonios de culto mitraico en el litoral de la Tarraconense", en Quaderns de Prehistoria i Arqueologia del Maresme. Mataró 1979, págs. 274-276 (con dibujo y fotografia); MAYER, M., FABRE, G., e RODA, I., 1983: 83-88, lám. 34 y fig. 11; idem, 1984: 129-139 y láms. XXIX-XXXIII; Prevost।, M., 209). 


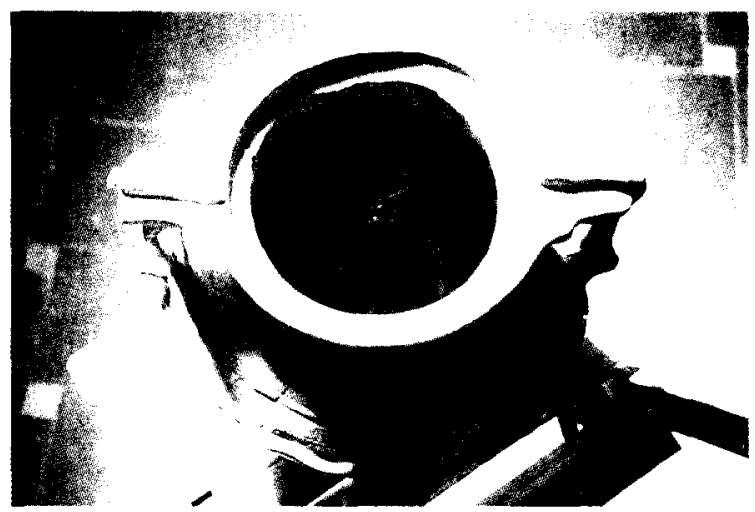

Fig. 16.2 Parte superior del vaso descubierto en Lugo en donde se aprecia

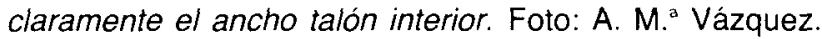

de que disponemos sobre este ejemplar son todavía insuficientes para poder determinar su atribución segura al culto mitraico. En consecuencia, esperamos que, tanto las investigaciones que en esta zona está efectuando su descubridor, E. Alcorta Irastorza, como nuestro propio estudio directo de dicha pieza, nos permitan determinar el posible carácter mitraico de este ejemplar. Por otra parte, de confirmarse la adscripción mitraica del mismo. se incrementaria con una nueva localidad la actual nómina de lugares hispanos con testimonios arqueológicos de este culto.

Desde el punto de vista iconográfico, un tercer testimonio hispano, aunque en este caso relivario, del uso de vasos en la liturgia mitraica lo tenemos en la porción de "tríptico" mitraico, con representación en altorelieve del Banquete de Mithra y Sol, descubierto en las ruinas de la antigua Caetobriga, Troya, junto a la desembocadura del río Sado, en Setúbal (Portugal). En la parte baja de la escena conservada aparece, entre los dadóforos mitraicos, la representación de una crátera rodeada por los anillos de la serpiente, que trata de introducir su cabeza en ella ${ }^{97}$ (fig. 17).

Finalmente, un cuarto testimonio lo podria constituir la decoración que representa una crátera entre dos grifos afrontados (los cryphii inte-

97 MARQues DA COSTA, A. I., "Estudos sobre algunas estaçoes da época luso-romana nos arredores de Setúbal", en $O$ Archeologo Português, vol. XXIX (1930-31), págs. 2-31; GARCIA Y BELLIDO, A., Op. cit., págs. 304-313, fig. 23, lám. 3, fig. 4; Idem, Esculturas romanas de España y Portugal. Madrid, 1949, págs. 394-399, lám. 282; Idem, Les Religions Orientales dans l'Espagne Romain, EPRO. Leiden 1967, págs. 36-37. 


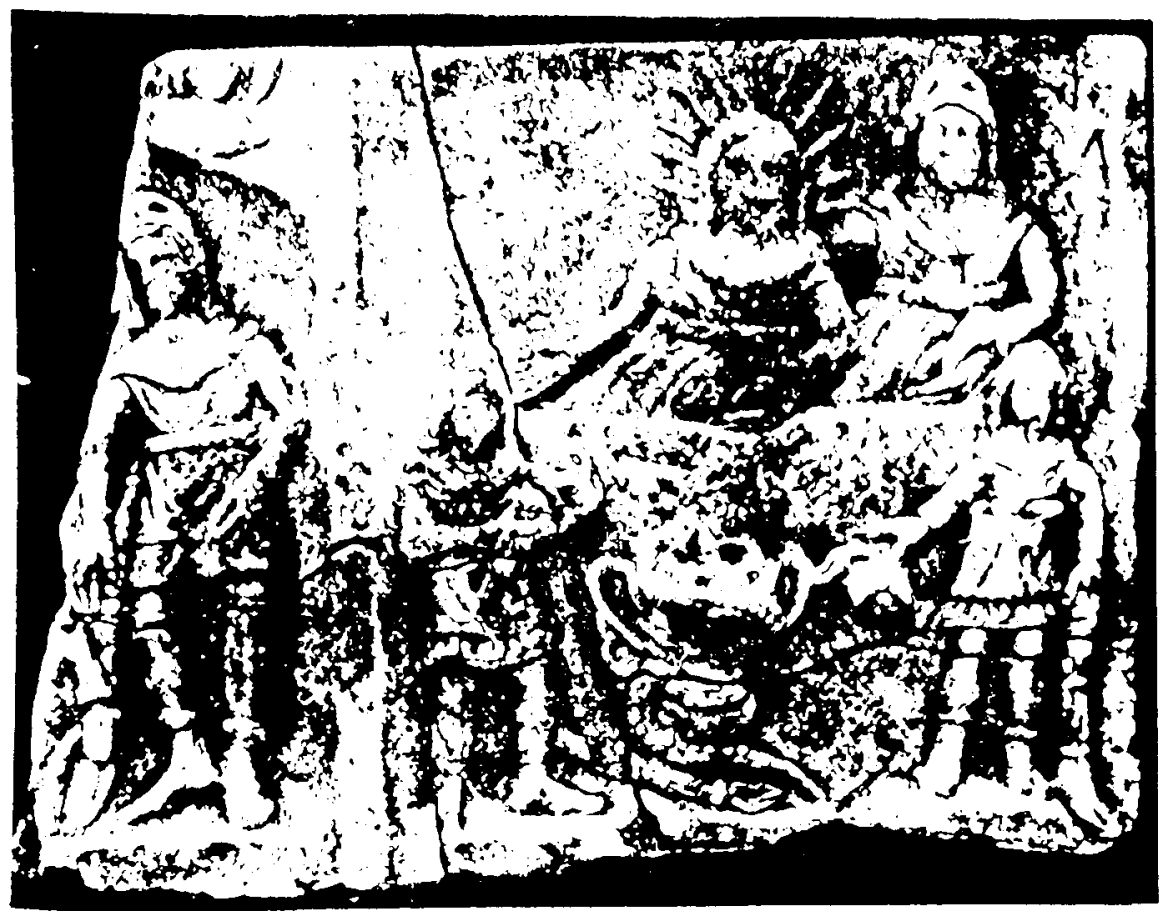

Fig. 17 Retablo (fragmento) con escena ritual de Banquete Mithra-Sol descubierto en Troya, Setúbal, (Portugal). En parte baja de la escena, entre Cautes y Cautopates, crátera rodeada por los anillos de una serpiente, que introduce su cabeza en el interior de la misma. Foto: V. Correia.

gran el segundo grado mitraico, no lo olvidemos), representada en Tarazona, la antigua Turiaso (fig. 18).

Según Turcan, la representación de siete vasos litúrgicos en la iconografía de algunos mitreos pudiera estar relacionada con su posible uso en las ceremonias de iniciación de cada uno de los grados mitraicos, celebradas en ellos ${ }^{98}$. Por otra parte, diversos autores han estudiado el

98 TURCAN, A., "Les autels du culte mithriaque", en Archèologie de l'espace sacrificiel, Colloque International CNRS (Lyon, 4-7 juin, 1988), 1989, pág. 229. Del mismo autor, cfr. Les cultes orientaux dans le monde romain. Paris 1989, pág. 219: "Sur une stéle d'Interamna (Terni) sept vases alignés sous l'antre sacrificiel répondent aux sept autels juxtaposés aut-dessus de la voûte: récipients censés contenir le sang de la victime, mais auquel le vin servait de subtitut dans les banquets mithriaques. Leur nombre s'accorde à celui des sept grades initiatiques", y núm. 80: CIMRM, 670 y fig. 191). 


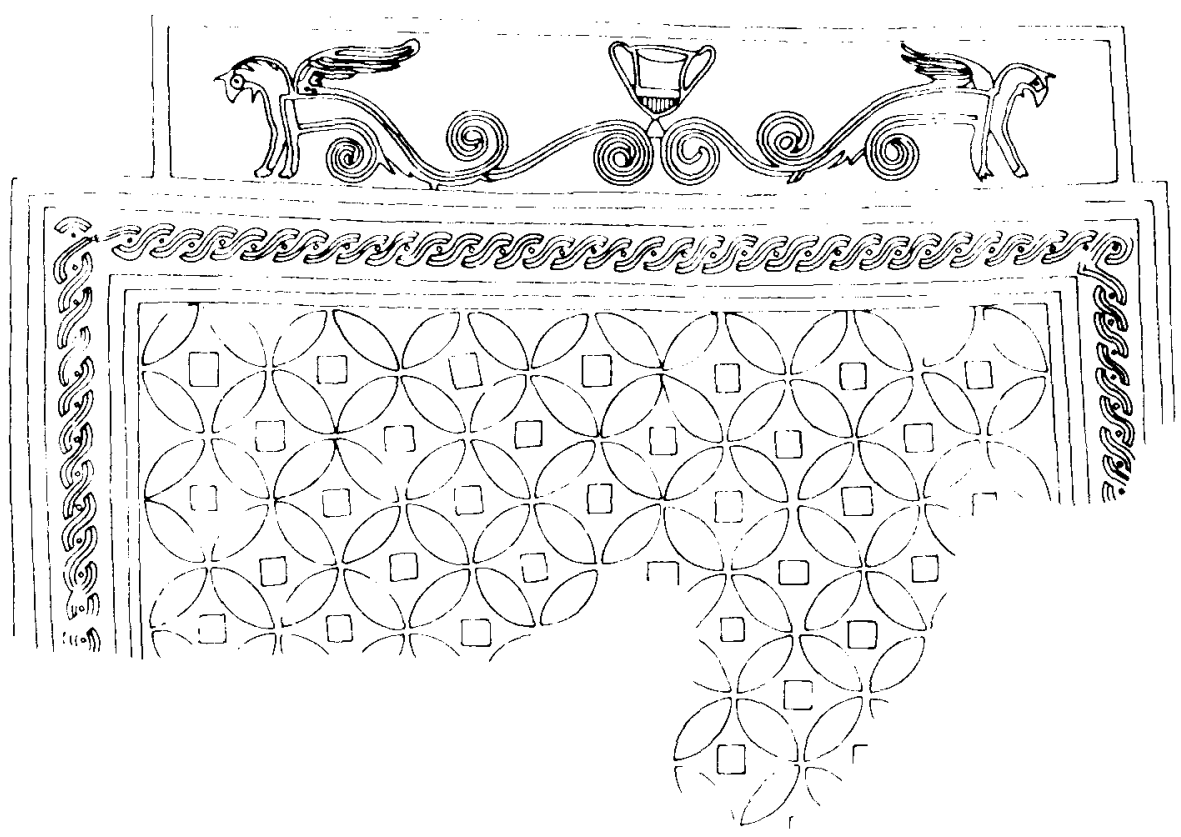

Fig. 18 Mosaico decorado con crátera representada entre grifos, descubierto en Tarazona, la antigua Turiaso. Museo de Tarazona.

probable significado de los motivos decorativos que aparecen sobre los vasos litúrgicos mitraicos. Vertet, por ejemplo, ha estudiado los motivos mitraicos del repertorio decorativo de la cerámica gala de Lezoux ${ }^{99}$, y Ogawa ha analizado concretamente la representación de una escala entre los motivos decorativos de la crátera mitraica de Friedberg (figs. 8,1 y 8,2), llegando a la conclusión - posible, desde luego- de que este recipiente se usaba concretamente para contener la miel que en los ritos mitraicos presentaba un miles a un leo en el curso de la iniciación de éste en la leóntica ${ }^{100}$. En tal sentido, podemos suponer que en cada uno de estos santuarios se guardarian, al menos, siete de estos vasos, cuyos motivos decorativos serían quizás los correspondientes a cada uno de los grados iniciáticos y cuyo uso estaría reservado a cada una de las respectivas ceremonias iniciáticas.

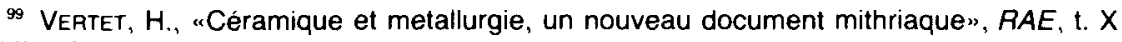
(1984), págs. 849 y ss.

100 Ogawa, H., Op. cit, pág. 872. 
De todo lo dicho se podrían inferir algunas otras conclusiones. El porcentaje de vasos mitraicos en el conjunto total de vasos con serpientes descubiertos en los territorios del antiguo Imperio Romano es minimo. $Y$ si bien es cierto que se hicieron vasos mitraicos en algunos talleres, no se conoce ninguno de ellos dedicado "exclusivamente» a esta actividad, sino que debieron tenerla como complementaria. De aquí la rareza de estas piezas. Quizás hubo relaciones entre algunos de estos talleres. Por otra parte, tampoco cabe atribuir la presencia de estos vasos únicamente a los mitreos, ya que aparecen en otros contextos arqueológicos no mitraicos, ni podemos centralizarla en determinadas regiones, ni mucho menos admitir su abundancia a lo largo del limes. Ni tampoco atribuir a la iconografía de la serpiente en estos vasos un sentido exclusivamente mitraico, ni siquiera cuando aparece formando parte de la famosa trilogia león-crátera-serpiente, trilogía cuyo simbolismo, al parecer, procede, como ya hemos señalado, de épocas mucho más antiguas y se proyecta a otras mucho más tardías.

Por su parte, Demarolle se plantea también la cuestión de si tales decoraciones pudieron haberse realizado por encargo expreso de los devotos de Mithra ${ }^{101}$, como opina Vertet al referirse a los ya mencionados vasos de arcilla de la Galia ${ }^{102}$, aunque V. J. Walters, en su sintesis, se opone a esta opinión, ya que, como dice, hasta el presente no se ha descubierto ningún indicio de la existencia de un mitreo en Lezoux, concluyendo que es posible que tales vasos estuvieran destinados a iniciados que no residian necesariamente en dicha localidad. También Demarolle manifiesta que, si bien el pequeño número de vasos descubierto hasta ahora puede haber hecho pensar en la validez de este argumento, nuevos descubrimientos podria echarlo por tierra, y cita algunos hallazgos cerámicos efectuados en los mitreos 0 en sus proximidades ${ }^{103}$. Únicamente en Trèveris se encontraron en las inmediaciones del Mitreo de Altbachtal algunas piezas de cerámica. Las demás se descubrieron en antiguos talleres de ceramistas. Esta segunda circunstancia, obliga a clasificar ciertos fragmentos cerámicos entre los objetos supuestamente con-

101 Cfr. Demarolle, J-M., Op cit., pág. 529 y núm. 91.

102 VERTET, $\mathrm{H}$., «Les representations mithriaques sur les vases d'argile en Gaul», Actes $88 e ́ m e$ Congrés des societés savantes (Clemont-Ferrand, 1963). Paris 1965, págs. 121-129

${ }^{103}$ Demarolle, J-M., Op cit., pág. 529, núm. 42. Cfr. también Walters, V. J., The cult of Mithras in the Roman provinces of Gaul, EPRO, 41. Leiden 1974, núm. 41: "On can assume neither that the potters themselves were aware of the symbolic significance of the scenes they portrayed, nor that they produced this work specifically for Mithraic worshippers". 
sagrados a Mithra, clasificándose concretamente como pertenecientes a vajillas litúrgicas.

Así, en Biesheim, en el área de un mitreo establecido hacia $140 \mathrm{~d}$. C. se han efectuado importantes descubrimientos. Sobre los fragmentos de una crátera de sigillata decorada con serpientes enroscadas en torno a las asas está grabada la inscripción VIT/D...; otro cubilete de engobe negro presenta la inscripción a la barbotina... DES/DIM. Podría tratarse, según Demarolle, de fragmentos de vajilla de cerámica marcada con el nombre de mystas y de consagrados ${ }^{104}$. Los ejemplos podrían ser más numerosos.

Estos materiales se podian comparar con los estudiados por W. Von Pfeffer ${ }^{105}$, así como con los de La Bâtie-Montsaleón (tres copas en tierra cocida con dedicatoria) o el bol con barniz rojo, conservado en el Museo de Gap. Este bol presenta una inscripción grabada en letra cursiva: DEO INVICTO MITHRAE VASSA DECEM TERTIUS RUSTICI V. S.L.L.M., que según CIL XIII 6068 y CIMRM II, 1302, procede de Rheinzabern, del mismo taller al que pertenece una parte de la vajilla de Biesheim. Coinciden con estos dos grandes vasos los fragmentos de una gran botella del tipo Dèchelette, decorada con una escena mitraica con figuras de la Luna, de Mithra, del Toro; y por último, sobre los fragmentos de un vaso tipo Drag. 37 la decoración no es menos claramente «mitraica». Esta vajilla es de origen regional ya que en su mayor parte ha sido fabricada en Rheinzabern ${ }^{106}$.

Sería, sin duda, inadecuado relacionar sistemáticamente la aparición de decoraciones religiosas orientales con el conocimiento de estas mismas religiones orientales. Y sería igualmente erróneo pensar que la aparición de tales decoraciones sobre el pobre soporte de la cerámica es el índice de una gran participación popular en tales cultos. En la actualidad no existe más que un pequeño número de tales documentos; si este número aumentase, en particular, en los vici -como parece estar comenzando a ocurrir - se impondrían nuevas posibilidades de interpretación.

104 Demarolle, J-M., Op cit., pág. 529 y núm. 43. Cfr. Petri, F., y Kern, E., “Un mithraeum à Biesheim", Cahiers Alsaciens d'Archèologie, d'Art et d'Histoire, 21, 1978, págs. 5-32.

${ }^{105}$ VON Pfeffer, H., "KultgefäB mit Mithrasdarstellung aus Mainz», Germania, 38 , 1960, págs. 145-146.

106 TURCAN, R., Les religions de l'Asie dans la vallée du Rône, EPRO, 30. Leiden 1972, págs. 37-38. Demarolle, J-M., Op cit., pág. 529 y núm. 45. 
En todo caso, no quisiéramos concluir este trabajo sin señalar que el estudio y la revisión de la cerámica desde estos puntos de vista de las religiones orientales, en nuestro caso, los Misterios de Mithra, pueden servir en un futuro próximo para un mejor conocimiento de las mismas en los antiguos territorios del Imperio romano, entre ellos, Hispania. 